\title{
ESPAÑA 1982: LAS ELECCIONES DEL CAMBIO*
}

Mario Caciagli

\section{UN CATACLISMO ELECTORAL}

La andadura de las elecciones de dos Parlamentos regionales (en octubre de 1981 y en mayo de 1982) había anticipado algunos aspectos y creado las premisas. Las vicisitudes del partido del Gobierno, esquilmado por escisiones y abandonos de sus máximos representantes, habían hecho previsibles los resultados. Los sondeos de las últimas semanas, en fin, los habían ya anticipado con bastante aproximación. Por todas estas razones los resultados de las elecciones para el tercer Parlamento de la España postfranquista, celebradas el 28 de octubre de 1982, no constituyeron una excesiva sorpresa.

En el apartado siguiente desarrollaré las tres etapas que habían poco a poco aproximado $\mathrm{y}$, por decirlo así, alertado sobre los resultados. Por lo pronto quiero decir que éstos, mirados con una cierta distancia, deben con todo considerarse desconcertantes. Para calificarlos no he podido encontrar término más adecuado que «cataclismo», como para otros casos, incluido el italiano, he utilizado «terremoto». ¿Qué otra expresión puede usarse para definir desplazamientos de votos que se cuentan por millones

* Publicado en Quaderni dell'Osservatorio Elettorale, n. 11, julio 1983. Reproducido con permiso del autor. 
( $\mathrm{y}$ en decenas de puntos porcentuales) y producen el crecimiento tumultuoso de algunos partidos y la caída vertiginosa de otros? En el panorama europeo de los últimos decenios - por referirnos a un área y un período histórico suficientemente homogéneos- es verdaderamente difícil encontrar algo similar ${ }^{1}$. Importantes trasvases de votos se registraron en las fases de asentamiento de los sistemas europeos, pero nunca en las proporciones del caso español. Teniendo en cuenta además que el electorado español había confirmado en las elecciones de 1979 las opciones principales de $1977^{2}$, hay que reflexionar sobre las transformaciones ocurridas. Intentaré hacerlo al final de este trabajo, discutiendo el sentido político del cataclismo electoral y las perspectivas del sistema de partidos.

En la parte central de este ensayo intentaré explicar la dimensión de este movimiento, analizando la distribución territorial del voto y elaborando hipótesis sobre el destino de los distintos flujos. Se podrá comprobar que las cifras se prestan a distintas lecturas, si se las considera en términos de bloques en vez de listas o partidos.

Quiero indicar ahora las características fundamentales de este excepcional éxito electoral. Son las siguientes:

- El clamoroso éxito de un partido (el PSOE) que, después de haberse estabilizado en las dos elecciones precedentes en torno al 30 por 100 de los votos, ha saltado de golpe a más de un 48 por 100 y ha conquistado así la mayoría absoluta de los escaños (empresa considerada anteriormente difícil para un partido español, dado un sistęma más bien proporcional, a pesar de fuertes correctivos).

- La caída de un partido en el Gobierno (UCD) que, después de afirmarse en dos elecciones consecutivas con un porcentaje de votos alrededor del 35 por 100 y llevar las riendas del país durante los cinco años de la transición, se precipitó a menos de un 7 por 100 (este hecho, más bien único que raro, es el más excepcional de las últimas elecciones españolas).

- El fuerte crecimiento, hasta de un 25,9 por 100 , de otro partido (AP, aunque en coalición con antiguos miembros de UCD), que había obtenido un 8,4 por 100 en 1977 , descendiendo en 1979 al 5,6 por 100, hasta el punto de que parecía destinado a desaparecer.

- El importante retroceso de un partido histórico (el PCE), protagonista de la resistencia al franquismo, que, al perder dos tercios de sus electores

' Cf. T. T. Mackie, R. Rose (eds.), International Almanac of Electoral History, Londres, Mac Millan, $1974 \mathrm{y}$, de los mismos autores, la reseña publicada anualmente en un número del European Journal of Political Research. Para los datos relativos a los países de la CEE cf. T. T. MACKIE, Elections in European Community Countries, University of Stratchlyde, Glasgow, 1979, cicl.

${ }^{2}$ Sobre las elecciones de 1977 y 1979 , respectivamente, consultar mi " 15 de junio en España", en los Quaderni dell'Osservatorio elettorale, 3 de julio de 1978, pp. 5-40, y "Las nuevas elecciones políticas en España", en Il Mulino, 262, marzo-abril de 1979, pp. 285-307. 
y conservar tan sólo cuatro diputados, corre el riesgo de quedarse fuera del escenario parlamentario.

Otros aspectos son sólo corolario de estos cuatro. El más interesante de los aspectos secundarios consiste en la relativa simplificación del sistema de partidos parlamentario. Si, por un lado, en el Congreso de los diputados ha entrado el nuevo partido de Adolfo Suárez, el Centro Democrático y Social (CDS), por el otro, no han vuelto los representantes de algunas de las listas regionales cuyo éxito había caracterizado las elecciones de 1979.

En conjunto hemos asistido a una reestructuración del sistema de partidos, debida especialmente a modificaciones internas de los dos bloques de derecha e izquierda. Es difícil creer, sin embargo, que las elecciones del 28 de octubre hayan sido "críticas», como algunos observadores se han apresurado a comentar, es decir, que marquen una redefinición de las opciones de voto destinada a perdurar por muchos años ${ }^{3}$. Es más fácil predecir nuevos movimientos para un futuro inmediato. El electorado español parece estar expuesto y disponible a nuevas conmociones.

El único elemento que puede hacernos pensar en una elección «crítica» es la implicación sensible de los electores que han percibido y vivido esta consulta como un cambio trascendental para la vida del país y el rumbo del sistema político. Ya se había mostrado en el curso de la campaña electoral seguida con una participación bastante más intensa que en la anterior. Los líderes, especialmente Felipe González y Manuel Fraga, habían logrado una audiencia que superó todas las previsiones. El punto más alto de la campaña fue el mitin de clausura de Felipe González en Madrid: con medio millón de participantes batió el récord de una manifestación política en España.

Un termómetro seguro para demostrar la tensión y expectación de los electores es su afluencia a las urnas. Este es el primer dato numérico sobre el que pienso detenerme.

Se debe precisar que las cifras de los electores y de los votantes en 1982 (el porcentaje ha sido a nivel naçional del 79,8 por 100 ) no pueden compararse directamente con las de 1977 y 1979. Las autoridades competentes procedieron de hecho a una revisión de las listas electorales, eliminando inscripciones dobles, residentes en el extranjero por tiempo indefinido, errores materiales. Aunque no existió una comunicación oficial, se dejó entrever que se había eliminado cerca del 5 por 100 del electorado. La operación de lim-

${ }^{3}$ Como se sabe, la definición de elección "crítica" proviene del ensayo de V. O. KEY, "A Theory of Critical Elections", en el Journal of Politics, febrero de 1955 , pp. 3-18. Es "crítica", según KEY, una elección que altera los cleavages existentes y opera una reestructuración del voto destinada a mantenerse durante bastantes elecciones sucesivas. Punto decisivo para KeY es que la reestructuración sea acentuada y capaz de durar. Obviamente, no sólo es imposible sostener desde ahora algo similar para el 28 de octubre en España, sino que todo parece indicar lo contrario para el futuro. Por otro lado, unas elecciones "críticas" implican una serie de fenómenos sociales y de crisis políticas que no se han registrado en España. 
pieza de las listas puede comprobarse al comparar el número de electores de 1979 y 1982 (véase más adelante el cuadro 4): el censo electoral ha aumentado tan sólo en 70.000 , cifra seguramente inferior al incremento demográfico correspondiente. Si el censo electoral estaba hasta ahora artificialmente inflado, el porcentaje de votantes en todas las consultas populares precedentes (que no tengo más remedio que utilizar en tanto que cifras oficiales) era siempre inferior a la realidad. Esto vale para el 79,1 por 100 de 1977 como para los años sucesivos.

Sin embargo, a pesar de la inexactitud de las cifras, el fenómeno que se aprecia es el de una constante disminución de afluencia a las urnas hasta 1982. Partiendo del 79,1 por 100 de 1977 , descendió a un 67,7 en el referéndum constitucional de diciembre de 1978, a un 68,3 en las legislativas de 1979 y por debajo de un 60 por 100 en las municipales y autonómicas de 1979-81. Los datos de 1979 sobre todo se consideraron como señal evidente de apatía y distanciamiento de las instituciones ${ }^{4}$.

El porcentaje de 79,8 por 100 del 28 de octubre de 1982, indica así un aumento sensible de la participación electoral en España, teniendo en cuenta, además, que este incremento ha sido ya depurado. Sin considerar los porcentajes y sin comparar el número de electores, salta a la vista la cifra importante y segura de tres millones de votantes más con respecto a 1979 (véase de nuevo el cuadro 4): una masa de electores con un gran peso en la distribución final del sufragio.

El aumento de la participación se ha registrado en casi todo el país (dejando a un lado las razones técnicas antes expuestas). Los datos por regiones nos permiten apreciar, sin embargo, fenómenos dignos de análisis.

Se ha registrado incluso un crecimiento del abstencionismo en tres regiones: La Rioja, Castilla-La Mancha y Baleares. Dadas las características socioeconómicas y políticas de estas tres zonas, este abstencionismo podría deberse a un electorado potencialmente conservador que no ha encontrado un partido al que poder entregar su voto. Por otro lado, es importante, desde un punto de vista político, que el aumento de la participación haya sido más alto en regiones como el País Vasco, Cataluña y Andalucía (es interesante subrayar que son regiones que gozaban ya de estatuto autonómico) y la Comunidad Autónoma de Madrid.

Las razones del aumento global en la afluencia a las urnas podrían ser las siguientes: en primer lugar (las pocas estimaciones que circularon en la prensa al día siguiente de los comicios lo han confirmado), ha debido aumentar la participación de los jóvenes y los obreros en los grandes centros urbanos. Los fenómenos de protesta que se advirtieron en 1979 disminuyeron ante las expectativas y deseos de que el «cambio» ocurriera realmente y de una forma apreciable. Los estratos sociales más politizados y más

- Consultar una vez más mi ensayo Las nuevas elecciones politicas en España, cit., en particular pp. 286-289. 
críticos sabían que su voto contaba de verdad esta vez para que esa alternativa se produjese. Junto a ellos, una masa considerable de electores pretendía conseguir una especie de pleibiscito para el PSOE a fin de legitimarlo definitivamente en la toma de poder.

Si se ha movilizado el electorado dispuesto a votar a los socialistas, también lo ha hecho, aunque en medida probablemente menor, el electorado conservador, precisamente para frenar la «avalancha» PSOE. En definitiva, la fuerte dialéctica, la tensión bipolar, han movilizado a las dos tendencias.

Queda por preguntarse si el interés por la contienda puede interpretarse como auténtica voluntad de participación y en qué medida el compromiso que supone el acto de votar puede indicar una consolidación de la democracia en España. Más tarde volveremos a este punto cuando lleguen las conclusiones. Veamos ahora cómo se llegó al 28 de octubre.

\section{LOS ANTECEDENTES: LAS ELECCIONES AUTONOMICAS EN GALICIA Y ANDALUCIA, LA CRISIS DE UCD Y DEL PCE, LOS SONDEOS DE LAS ULTIMAS SEMANAS}

A la vista de lo que después ocurrió, la primera señal de que se estaban produciendo cambios en el electorado fueron los resultados de las elecciones para el Parlamento de la Comunidad Autónoma de Galicia, realizadas el 20 de octubre de 1981.

Al voto gallego, es verdad, no se le consideró como test significativo: concernía a poco más de dos millones de electores, de los cuales menos de la mitad (46,2 por 100), según la tradición local, se desplazó a las urnas, y procedía de una región marginada con características muy particulares y con un comportamiento electoral bastante anómalo ${ }^{5}$.

El aspecto más relevante de las elecciones en Galicia fue el éxito de Alianza Popular, que se convirtió en el primer partido en votos y escaños (véase cuadro 1), y, por tanto, obligada a formar gobierno autónomo con el apoyo de UCD. El hundimiento de este último partido podría explicarse mediante razones de carácter local, con el cambio de humor de una región atrasada e inquieta. Los hombres de Fraga se habían aprovechado de los errores del partido del gobierno y de sus luchas internas, se habían asegurado el apoyo de las asociaciones patronales y autoridades eclesiásticas de la región, utilizando reacciones emotivas y sus específicos instrumentos caciquiles. La derrota de UCD, aunque alarmante, se la consideró normal en las elecciones autonómicas (como ocurrió en el País Vasco y Cataluña en 1980) y se pensó que no habría de tener repercusiones en el plano nacional.

5 A propósito, cfr. J. PÉREZ VILARIÑo, "Comportamiento electoral en Galicia", en Papers, 14, 1980, pp. 49-67. 
A la consolidación del ala más derechista del bloque conservador se correspondió un avance general de la izquierda, del que se aprovechó particularmente el PSOE, quitándole votos a la UCD y al PCE. Era otro signo premonitorio, no valorado en su justa medida por los observadores ${ }^{6}$.

\section{CUADRO 1}

Resultados de las elecciones para el Parlamento gallego en 1981 y comparación con las elecciones para el Congreso de los Diputados de 1979 (porcentajes)

\begin{tabular}{|c|c|c|c|}
\hline & $\begin{array}{c}\text { Parlamento } \\
\text { gallego, } \\
20 \text { octubre } 1981\end{array}$ & $\begin{array}{l}\text { Congreso de } \\
\text { los Diputados, } \\
1 \text { marzo } 1979\end{array}$ & $( \pm)$ \\
\hline 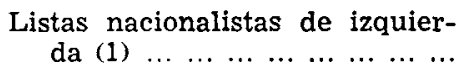 & 13,0 & 11,5 & $(+1,5)$ \\
\hline $\begin{array}{llllllllll}P C & (G) & \ldots & \ldots & \ldots & \ldots & \ldots & \ldots & \ldots & \ldots\end{array}$ & 2,9 & 4,1 & $(-1,2)$ \\
\hline $\begin{array}{lllllll}\text { PSOE }(P S G) & \ldots & \ldots & \ldots & \ldots & \ldots & \ldots\end{array}$ & 19,6 & 17,3 & $(+2,3)$ \\
\hline $\begin{array}{lllllllllll}\mathrm{UCD} & \ldots & \ldots & \ldots & \ldots & \ldots & \ldots & \ldots & \ldots & \ldots\end{array}$ & 27,8 & 48,5 & $(-20,7)$ \\
\hline $\begin{array}{llllllllll}\mathbf{A P} & \ldots & \ldots & \ldots & \ldots & \ldots & \ldots & \ldots & \ldots & \ldots\end{array}$ & 30,5 & 14,0 & $(+16,5)$ \\
\hline $\begin{array}{lllllllllll}\text { Otros } & \ldots & \ldots & \ldots & \ldots & \ldots & \ldots & \ldots & \ldots\end{array}$ & 6,2 & 4,6 & $(+1,8)$ \\
\hline Total $\ldots \ldots \ldots \ldots$ & 100,0 & 100,0 & \\
\hline
\end{tabular}

(1) En el Bloque Nacional Popular Gallego y Unidad Gallega; en 1981, Bloque Nacional Popular Gallego (unidos en lista), Partido Galleguista e Izquierda Gallega.

Bastante más sintomáticas, llenas de advertencias y consecuencias, fueron más tarde las elecciones para el Parlamento de la Comunidad Autónoma de Andalucía, el 25 de mayo de 1982. Los 4.300 .000 electores andaluces constituyen cerca de un sexto del electorado español (a pesar de que solamente el 60 por 100 votó); en esa región UCD había sido capaz de competir con el PSOE por la mayoría relativa en el marco de un comportamiento electoral preferentemente orientado hacia la izquierda (que había favorecido tanto al PCE como a los autonomistas del PSA); los problemas sociales y económicos (y por tanto los acontecimientos políticos) de la región son cruciales para la España contemporánea. Finalmente, debido al momento en el que se desarrollaban estas elecciones, fueron abiertamente consideradas como ensayo general de las legislativas, hasta el punto de condicionar el inmediato desarrollo político.

- Véase el atento análisis de J. J. González EnCINAR, "El supuesto giro a la derecha en las elecciones al Parlamento gallego", Revista de Estudios Políticos, enerofebrero de 1982, pp. 53-79. 
Por esta razón el gobierno se implicó intensamente, anunciando medidas típicamente electorales, prometiendo inversiones, llevando ministros para la inauguración de obras públicas. UCD realizó un considerable esfuerzo propagandista, pidiendo y consiguiendo el apoyo de organizaciones patronales. Estas, preocupadas por frenar el avance del PSOE, después de haber presionado para conseguir la elaboración de una sola lista unida de centroderecha, no hicieron distinciones, en sus declaraciones y acciones de apoyo, entre los dos partidos conservadores; sin embargo, sus representantes locales apoyaron abiertamente a Alianza Popular.

En la dirección de AP Fraga había planteado una batalla muy dura («en Andalucía -declaraba - está en juego el modelo de sociedad») y había propuesto la creación de un bloque conservador para contraponerlo al «frente marxista». Sin embargo, UCD rechazó una posible alianza y la línea de propaganda de Fraga, pensando, como todavía hacían creer los sondeos en vísperas de elecciones, que conseguirían con comodidad ser el segundo partido: sus dirigentes habían declarado que el límite mínimo tolerable y posible sería un 20 por 100 . Tan dramático fue su fracaso que dio origen a la crisis autodestructiva de los meses siguientes y anticipó la derrota de las elecciones generales.

En conjunto, como demuestra el cuadro 2, el trasvase de votos había adquirido ya grandes dimensiones en Andalucía?

\section{CUADRO 2}

Resultados de las elecciones para el Parlamento andaluz en 1982 y comparación con las elecciones para el Congreso de los Diputados de 1979 (porcentajes)

\begin{tabular}{|c|c|c|c|}
\hline & $\begin{array}{l}\text { Parlamento } \\
\text { andaluz, } \\
25 \text { mayo } 1982\end{array}$ & $\begin{array}{l}\text { Congreso de } \\
\text { los Diputados, } \\
\text { I marzo } 1979\end{array}$ & $( \pm)$ \\
\hline 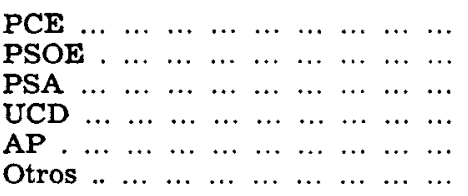 & $\begin{array}{r}8,5 \\
52,6 \\
5,4 \\
14,5 \\
17,0 \\
2,0\end{array}$ & $\begin{array}{r}13,2 \\
33,7 \\
10,6 \\
31,5 \\
4,3 \\
6,7\end{array}$ & $\begin{array}{l}(-4,7) \\
(+18,9) \\
(-5,2) \\
(-17,0) \\
(+12,7) \\
(-4,7)\end{array}$ \\
\hline 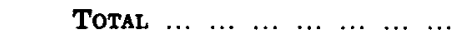 & 100,0 & 100,0 & \\
\hline
\end{tabular}

${ }^{7}$ Obtengo todas las cifras, como las informaciones sobre la campaña electoral, de mi colección de recortes de prensa. Se puede encontrar un análisis detallado en P. Brabo y C. Ortiz, "Una interpretación política de las elecciones andaluzas", en Leviatán, otoño 1982 , pp. 63-74. 
UCD había perdido más de la mitad de sus votos con respecto a 1979, en números absolutos casi medio millón. El freno del Gobierno central al proceso autonómico no podía ser razón suficiente para tal desastre: había contribuido también a la caída vertiginosa de la credibilidad del partido la débil imagen de sus candidatos y el deslizamiento del apoyo de los empresarios locales a AP. Una parte del electorado centrista se refugió en la abstención, otra se desplazó al PSOE, pero indudablemente la más consistente se fue a la derecha, es decir, a AP. El éxito de este partido fue todavía más significativo que en Galicia, ya que partió de un nivel todavía más bajo (el 4,3 por 100 de 1979 se convirtió en un 17 por 100 en 1982).

El verdadero triunfador en Andalucía fue el PSOE. Su fuerza electoral, frenada en 1979 por el voto al PSA, creció en dos tercios y superó el 50 por 100: por vez primera un partido conseguía esta meta en elecciones celebradas en la España postfranquista.

Su millón de votos era tres veces el número conseguido por $\mathrm{AP}$, el segundo partido. Un análisis de las tendencias electorales demostraba que en el PSOE habían confluido ex votantes de UCD (por lo menos 200.000, equivalente a un 5,6 por 100), logrando los socialistas grandes avances en zonas tradicionalmente moderadas, la mitad de los del PSA (170.000, casi un 5 por 100) y parte de los del PCE (otros 150.000).

El Partido Socialista de Andalucía sufrió, tras el éxito de 1979, una importante derrota. Para explicarla es suficiente anotar su ambigua posición con respecto al centro (el apoyo frecuente de sus cinco diputados a los gobiernos centristas) y la puesta en marcha de la autonomía, que prácticamente le había quitado su caballo de batalla.

Grave fue también el retroceso del PCE en una de las regiones donde había tenido más aceptación y más afiliados e influencia en la administración local. El 8,5 por 100 conseguido estaba lejos del 13,2 por 100 de 1979 y todavía más del 17,9 por 100 en las municipales del mismo año. El electorado rural se mantuvo más fiel al PCE, pero en los centros urbanos tuvo tanto peso el voto «útil» hacia el PSOE como la crisis del partido sufrida también en Andalucía.

Triunfo del PSOE, caída de UCD, avance de AP, retroceso del PCE, descenso de los andalucistas y todo en proporciones considerables: en el voto autonómico andaluz del 25 de mayo estaban ya presentes todos los ingredientes de las futuras elecciones generales. Estas deberían de haberse realizado en la primavera de 1983, si precisamente los resultados de Andalucía no hubieran desencadenado el proceso de disolución de UCD que obligó al gobierno de Calvo Sotelo a intentar salvar lo poco salvable con unas elecciones anticipadas en octubre.

La primera escisión en UCD se remonta a 1981, cuando Francisco Fernández Ordóñez salió, a la cabeza de un grupo de diez diputados y seis senadores del ala socialdemócrata, para fundar el PAD, el Partido de Acción Democrática. Los resultados en Galicia habían alentado los deseos del ala 
conservadora de inclinar al partido del gobierno a una alianza con AP para conseguir así la «mayoría natural» de la gran derecha. Tan sólo el antiguo jefe del grupo parlamentario, Miguel Herrero, había dejado UCD en febrero. Durante todo el invierno y la primavera se sucedieron continuos rumores sobre la intención de Adolfo Suárez de abandonar también el partido: de hecho el líder de la transición se había cerrado en un diplomático silencio y había evitado tomar parte en la campaña electoral andaluza.

Los desastrosos resultados en Andalucía encaminaban al partido a su destrucción. En las semanas siguientes los grupos y las «familias» del grupo mantenian reuniones separadas, mientras crecían las presiones de Fraga para una alianza preelectoral y hasta se difundían previsiones sobre la inminente disolución del partido. A finales de junio el grupo de origen democristiano, presidido por Oscar Alzaga, dejaba el partido para formar uno nuevo al mes siguiente, el Partido Demócrata Popular (PDP) que, en seguida, llegó a un acuerdo con AP. Suárez esperó todavía algunas semanas antes de tomar una decisión en julio y formar a su vez el Centro Democrático y Social (CDS). Mientras tanto y bajo la iniciativa del liberal Antonio Garrigues Walker, se creó el Partido Demócrata Liberal (PDL), dispuesto a acoger a nuevos tránsfugas.

Las continuas deserciones, por sectores o individuales, reducían el grupo parlamentario, dejándolo en 123 diputados de los 168 elegidos tres años antes. El gobierno se arriesgaba a perder el apoyo parlamentario. Por este motivo, más que por razones políticas (detener la hemorragia de diputados, evitar la consolidación de Suárez con su nuevo partido y frenar a tiempo a AP), Calvo Sotelo se vio obligado a disolver las Cortes con antelación, el 29 de agosto. Era la última carta para conservar el electorado moderado y cortar el camino a los socialistas.

Estos, por su parte, estaban ya preparados para el enfrentamiento definitivo. Eran los demás los que criticaban la drástica decisión: los que deseaban una coalición de derecha, Suárez con un partido reducido y sin medios, los comunistas atenazados por una grave crisis. Conviene recordar ahora brevemente la crisis del PCE, precisamente porque sirve para explicar el resultado electoral de este partido.

El abandono de dirigentes y militantes (y de potenciales electores, como revelaban los sondeos) del PCE había empezado en 1980. Vino después el XVII Congreso, en julio de 1981, escenario de acalorados enfrentamientos entre grupos y tendencias: la mayoría en torno a Santiago Carrillo tuvo que enfrentarse a renovadores y eurocomunistas, a leninistas y prosoviéticos. En octubre de 1981 tuvo lugar la ruptura con el Partido Comunista Vasco, que prefirió unirse a Euzkadiko Ezkerra. En noviembre, precisamente por su desacuerdo hacia las medidas tomadas contra Roberto Lertxundi y los otros vascos, fueron relevados de sus cargos algunos dirigentes del Comité Central (entre los que se encontraba Manuel Azcárate) y de la fede- 
ración madrileña ${ }^{8}$. En marzo de 1982, finalmente, maduró la larga crisis del PSUC, el partido comunista catalán: los prosoviéticos abandonaron el PSUC para crear, en abril, el Partido de los Comunistas Catalanes (PCC), con la firme intención de presentarse a las elecciones.

La crisis del PCE se había extendido a todas las regiones, y era tan grave por ser particularmente aguda en las zonas con larga tradición, como el País Vasco, o con mayor fuerza electoral, como Cataluña y la provincia de Madrid. Las primeras consecuencias se vieron en Andalucía, donde a los numerosos abandonos, por diversas razones y a todos los niveles, siguió el fracaso electoral. Por estos motivos los dirigentes del PCE no estaban interesados en afrontar una confrontación electoral en breve plazo.

Después de la disolución de las Cortes, los sondeos cada vez más concretos confirmaban los temores o las esperanzas de los partidos contendientes. Los sondeos pueden considerarse también como antecedentes del resultado de las elecciones de 1982, en el sentido de que podrían haber influido en la decisión de los electores, a juzgar por la incertidumbre expresada esta vez también en España, como ha ocurrido ya en otros países a propósito de la publicación de ciertos datos a pocos días de las votaciones.

Sea como fuere, recuerdo que las encuestas de opinión habían señalado ya el ascenso del PSOE y el declive de UCD desde la primavera de 1980. Estas tendencias se habían agudizado después de la caída de Suárez y tras el intento de golpe de Estado, en febrero de 1981: la dimisión de Suárez había dejado al líder del PSOE solo, y con un amplísimo margen, a la cabeza de las preferencias de los entrevistados; además, el hecho de que se hubiera superado ya el peligro para el sistema democrático había hecho subir todavía con más rapidez la cotización de su partido. Durante el verano de 1981 se registró ya el primer gran descenso en la intención de voto a UCD y el salto definitivo a la cabeza del PSOE. Eran demasiadas las preguntas sin respuestas, demasiado altos los porcentajes de los indecisos para que valga la pena dar aquí las cifras. Quiero resaltar simplemente que la UCD todavía se mantenía, por un gran margen, como el segundo partido ${ }^{9}$.

Fue en la primavera siguiente, y sobre todo a raíz de la crisis en el verano de 1982, cuando las preferencias hacia el partido del gobierno descendieron bruscamente. En el último período preelectoral, como se puede ver en el cuadro $3, \mathrm{AP}$ superó a UCD, que seguía descendiendo, mientras su rival de derechas crecía progresivamente.

- Acerca de muchos de estos hechos consultar P. Vega, P. Errotera, Los herejes del PCE, Barcelona, Planeta, 1982, y también como testimonio de un protagonista, M. Azcárate, Crisis del Eurocomunismo, Barcelona, Argos Vergara, 1982.

9 Me refiero a los principales sondeos publicados, en un bienio, por la prensa. Para el análisis del proceso existe alguna indicación en J. M. ARIJA, "Huyen los centristas", en Cambio 16, 7 de junio de 1982. 
Las cifras del cuadro indican cómo la tendencia de voto señalada en los sondeos anticipó los resultados con una aproximación tan sorprendente como grande era la dimensión del cataclismo que se avecinaba.

\section{CUADRO 3}

Resultados de algunos de los sondeos realizados en el último mes antes de las elecciones y distribución porcentual de los votos de los mayores partidos en las elecciones para el Congreso de los Diputados

\begin{tabular}{|c|c|c|c|c|c|}
\hline Partidos & $\begin{array}{c}\text { Diario } 16 \\
1^{\circ} \\
\text { (1) }\end{array}$ & $\begin{array}{c}\text { Diario } 16 \\
2^{\circ} \\
(2)\end{array}$ & $\begin{array}{c}\text { Diario } 16 \\
3 . \\
(3)\end{array}$ & $\begin{array}{c}\text { El Pais } \\
\text { (4) }\end{array}$ & $\begin{array}{l}\text { Resul- } \\
\text { tados }\end{array}$ \\
\hline 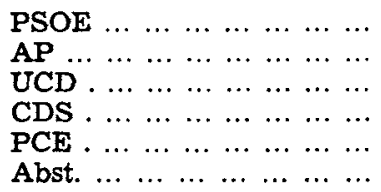 & $\begin{array}{r}51,0 \\
13,0 \\
10,7 \\
5,2 \\
6,0 \\
13,0\end{array}$ & $\begin{array}{r}45,9 \\
16,3 \\
10,6 \\
8,4 \\
5,0 \\
14,4\end{array}$ & $\begin{array}{r}49,2 \\
18,2 \\
9,5 \\
5,9 \\
7,8 \\
12,3\end{array}$ & $\begin{array}{r}42,9 \\
21,2 \\
5,7 \\
3,5 \\
5,2 \\
21,5\end{array}$ & $\begin{array}{r}48,4 \\
25,9 \\
6,8 \\
3,7 \\
4,0 \\
20,2\end{array}$ \\
\hline$N=$ & 1.560 & 3.008 & 7.000 & 18.255 & \\
\hline
\end{tabular}

(1) Fuente: Diario 16 del 24 de septiembre de 1982 . Encuesta realizada por Alef para el periódico a mediados de septiembre. Tendencia de voto.

(2) Fuente: Diario 16 del 8 de octubre de 1982. Encuesta realizada por Alef el 30 de septiembre de 1982 . Tendencia de voto.

(3) Funnte: Diario 16 del 22 de octubre de 1982 . Encuesta realizada por Alef del 9 al 14 de octubre de 1982 . Tendencia de voto.

(4) Fuente: El País del 22 de octubre de 1982. Encuesta realizada para el diario por Sofemasa del 16 al 19 de octubre de 1982.

El porcentaje de votos al PSOE de la encuesta de Alef se aproxima a los resultados; los porcentajes más bajos de la encuesta de Sofemasa se explican por el número mayor de abstenciones, pero contribuyen a consideraciones generales que haré dentro de poco. La intención de voto a $\mathrm{AP}$, como ya anticipé, crece continuamente a lo largo del mes. En los sondeos la caída de UCD era indudable; incluso la encuesta de Sofemasa predecía resultados inferiores a los que en realidad obtuvo UCD. Más cercanas estaban las cifras de la encuesta de Sofemasa con respecto a los porcentajes de voto de CDS y PCE, ambos sobrevalorados en las otras encuestas.

Parece plausible que los partidos minoritarios hayan sufrido, en la última fase, lã creciente polarización entre el PSOE y AP. El dato más seguro en todos los sondeos, desde hacía meses, era el arrollador avance del PSOE. Las perspectivas pudieron convencer a última hora a una parte de los electores conservadores, quizá más propensos a la abstención, para depositar su voto en el único dique seguro contra los socialistas, AP. En el polo opuesto, 
la expectativa de una victoria socialista (la «crónica de una victoria anunciada», como se ha dicho parafraseando un título de García Márquez), en vez de provocar efectos negativos de desconfianza y desinterés, como temían los dirigentes del PSOE, tuvo sin embargo un efecto movilizador tanto en el electorado de izquierdas (con grave perjuicio para el PCE y otras formaciones menores) como en el de centro o los abstencionistas (como indicaban las cifras de Sofemasa y señalé a propósito del crecimiento en la participación ciudadana). El 51 por 100 al PSOE anticipado por la primera encuesta de Alef podía considerarse como una tendencia en el voto, extrapolada por una serie de cifras diversas, sin embargo la popularidad cada vez más alta de González, aceptado por la mayoría (el 60 por 100) como futuro presidente de gobierno, y los porcentajes que superaban unánimemente los mínimos necesarios, permitían predecir con toda seguridad que los socialistas conquistarían la mayoría absoluta de los escaños.

\section{LAS CIFRAS DEL CAMBIO}

Ni siquiera el documento de la conferencia episcopal a finales de septiembre, veladamente hostil hacia un futuro gobierno socialista ${ }^{10}$, ni las polémicas en torno al viaje del Papa (previsto para la mitad de octubre, pero retrasado oportunamente a la semana siguiente de las elecciones) conseguían frenar el ascenso del PSOE en la preferencia del electorado. Este ascenso encontraba incluso nuevos incentivos ${ }^{11}$.

El primero fue la noticia de un nuevo complot militar preparado para la víspera de las elecciones y descubierto el 2 de octubre. Verdadera o falsa, la amenaza de golpe no podía ya funcionar como chantaje ${ }^{12}$. Incluso el recuerdo amargo del 23 de febrero de 1981 apenas se utilizó en el curso de la campaña; por el contrario, aquel atentado a la democracia y aquel ultraje

10 Desde la muerte de Franco, la Iglesia no había hecho público nunca un documento tan decididamente político. Si por un lado tampoco había aceptado con tanta claridad la defensa de las instituciones democráticas y seguía haciendo algunas críticas a la Constitución, por el otro se entrometía en la campaña electoral apelando al "elector cristiano". A pesar de reafirmar su intención de mantenerse alejado de todo programa político y de no tomar partido por ningún grupo, el episcopado daba a entender que la elección de los creyentes no podía dejar de tener en cuenta la condena del divorcio y el aborto, o la defensa de la enseñanza privada y de la institución familiar (puntos divergentes de los programas de la izquierda y en particular del PSOE).

"Sobre las condiciones de los otros partidos y acerca del clima preelectoral, ambos favorables al PSOE, véase J. M. REVERTE, "Una mayoría para el cambio: actores, escenario y guión", en Leviatán, 9 de octubre de 1982, pp. 33-39 y, en italiano, P. Cimo, "L'occasione socialista", en Mondoperaio, 9 de septiembre de 1982, pp. 51-57.

12 Sobre las tentativas de golpe y sobre la actitud de los militares en el postfranquismo véase C. FERnÁNDEZ, Los militares en la transición política, Barcelona, Argos Vergara, 1982. Más político el pequeño volumen de J. L. Morales, J. CELAdA, La alternativa militar. El golpismo después de Franco, Madrid, Editorial Revolución, 1981. 
al Parlamento contribuyeron a ampliar el consenso hacia los socialistas. Los electores se habían inmunizado contra el «voto del miedo». Si alguien había pensado que de este modo sectores del electorado volverían a la derecha, utilizó un boomerang.

El otro elemento que ayudó a conseguir el éxito socialista fue la división y confusión que reinaban en los partidos de centro-derecha. Explicaré más adelante cómo la división de UCD y del conjunto de centro-derecha favoreció al PSOE como consecuencia de los mecanismos electorales y seguramente en términos de escaños. Basta aquí con destacar cómo el potencial elector moderado acabó por quedar desorientado, inclinándose más que a otra cosa a la abstención. El mismo elector quedó también desorientado por el espectáculo de maniobras y pactos entre personas en busca de un escaño seguro $y$ entre nuevos y viejos partidos en busca de alianzas con garantías de éxito.

En el continuum centro-derecha/centro-izquierda, al menos cinco partidos estaban potencialmente en liza para ocupar el lugar de UCD. El PAD de Ordóñez había llegado desde hacía tiempo a un acuerdo con el PSOE para la inclusión de algunos de sus candidatos en las listas socialistas. El PDL de Garrigues Walker había intentado una alianza con UCD, sin embargo, en el último momento, decidió no presentarse. El PDP, que agrupaba prácticamente al ala democristiana escindida de UCD de la mano de Alzaga, llegó rápidamente a un acuerdo con AP para la formación de listas comunes ${ }^{13}$. La gran novedad podría ser el CDS de Suárez: su oferta de una alternativa reformista no de izquierdas, la esperanza de poder condicionar desde el exterior a un gobierno socialista sin posible mayoría absoluta, la imagen de su líder, sobre todo, hacían pronosticar para el CDS un papel de cierto peso en el nuevo Parlamento, ocupando naturalmente un espacio de centroizquierda. En el centro (mejor dicho «centro-centro», como decía su nuevo líder Landelino Lavilla) ${ }^{14}$ UCD pretendía llegar a mantener gran parte de los apoyos del pasado.

Los dirigentes de UCD, convencidos de poder influir todavía en el futuro sistema de partidos, rechazaron cualquier presión para constituir una gran coalición de centro-derecha con AP. La alianza antisocialista la propugnó Fraga hasta la víspera del cierre de las candidaturas (el 14 de septiembre), siendo al mismo tiempo alentada por numerosos representantes del mundo empresarial y de los otros «poderes fácticos». El haber resistido a tantas presiones perjudicó ciertamente a UCD, haciéndole pagar un precio todavía más alto en el recuento de las urnas ${ }^{15}$.

${ }^{13}$ Formaban parte de la coalición electoral tres partidos regionalistas: el Partido Aragonés Regionalista, la Unión del Pueblo Navarro y la Unión Valenciana.

${ }^{14}$ Landelino Lavilla era el líder del ala democristiana que quedó en UCD. Su elección como presidente del partido en el puesto de Calvo.Sotelo fue uno de los últimos intentos para salvar la unidad de UCD y su imagen ante el electorado.

${ }^{15}$ UCD se presentaba en coalición con AP y PDP únicamente en las tres provincias vascas de Guipúzcoa, Vizcaya y Alava. 
Tampoco por la extrema derecha AP conseguía tener los flancos bien cubiertos. Blas-Piñar, diputado saliente, presentaba de nuevo su lista de Fuerza Nueva-Unidad Nacional, mientras, entre otros grupos sin posibilidades reales, se presentaba también, provocando un exagerado temor en todos, Solidaridad Nacional encabezada por el teniente coronel Antonio Tejero, encarcelado y bajo proceso.

Finalmente, estaban los partidos nacionalistas moderados bastante más fuertes esta vez, como el Partido Nacionalista Vasco y Convergencia i Unió de Catalunya.

Frente a una confusa y siempre en litigio agrupación de centro-derecha, el campo de la izquierda se presentaba bastante más despejado y por tanto visible para el elector común. También había novedades por esta parte, pero todas estaban encaminadas a reforzar al partido mayoritario.

Desaparecieron, o tuvieron bastante menor peso, algunas de las listas autonomistas de izquierda que en 1979 habían indudablemente perjudicado al PSOE. La más importante, el Partido Socialista de Andalucía, sufrió un duro golpe precisamente en su propia región, en las elecciones de mayo - como ya se ha visto-. A nivel estatal, la renuncia a presentarse de algunos grupos extraparlamentarios podría haber beneficiado al PSOE en cierta medida, al estar dispuestos algunos de sus seguidores a votar socialista a favor del «cambio» a pesar de la moderación y cauto reformismo del programa del futuro partido de gobierno. El PSOE, en fin, podía permitirse rechazar con toda tranquilidad una oferta de alianza con el PCE, al ser consciente de la debilidad de este último. Sobre la crisis del PCE ya he hablado antes: en su destino electoral contaban también las amenazas de nuevas listas con denominación comunista (el Partido Comunista catalán y el Partido Comunista del pro-soviético Líster).

Es tiempo de pasar a los resultados del 28 de octubre de 1982. Los cuadros y gráficos que siguen a continuación, relativos a las elecciones para el Congreso de los Diputados, requieren una larga advertencia preliminar que haría con gusto si las fuentes oficiales sobre los datos electorales no continuasen presentando demasiados problemas y suscitando inevitables sensaciones de perplejidad.

En lo que concierne al cuadro 4, recogi las cifras absolutas y los porcentajes de 1979 del volumen editado en 1980 por el Instituto Nacional de Estadística (INE), ya que todavía hoy parece la fuente más fiable ${ }^{16}$.

He reconstruido, sin embargo, las cifras absolutas de los electores, de los votantes, de los votos válidos, del voto nulo y en blanco de 1982 a partir del cuadro 1: Resumen general, editado en diciembre de 1982 por la

${ }^{16}$ Instituto Nacional de Estadística, Elecciones generales. legislativas del $10^{\circ}$ de marzo de 1979, Madrid, 1980. 
Junta Electoral Central ${ }^{17}$, y las cifras absolutas de los votos conseguidos por cada partido en los cuadros 2 y 3 , publicados por la misma Junta ${ }^{18}$. He calculado los porcentajes a nivel estatal sobre estas cifras. He calculado los porcentajes de los tres partidos principales (cuadro 6) sobre los números absolutos suministrados por la Junta Central en el volumen de actas de las juntas provinciales, no publicado hasta marzo de $1983^{19}$.

Sin embargo, el resultado de estas operaciones no es del todo satisfactorio. Esto es debido a que tanto los cuadros generales como las actas provinciales tienen lagunas e incluso errores. Algunos de estos errores los descubrieron dos estudiosos que hicieron un paciente trabajo de comprobación, especialmente en el cuadro $1^{20}$. He tenido en cuenta sus advertencias, corrigiendo aquello que podía rectificar o volver a calcular. Las cifras incluidas en la parte inferior del cuadro 4 (las cifras globales) pueden ser todavía susceptibles de retoques.

Por lo que respecta a los cuadros 2 y 3 (votos a los partidos y a las listas por provincia y en total) puede recordarse que para un total de 35 provincias la suma de votos conseguida por todos los partidos no coincide con la suma de votos válidos y que existen lagunas con respecto a las listas que no han conseguido escaños (así la cifra del término «otros» se ha consegui-

17 Junta Electoral Central, Resumen de los resultados de las elecciones para el Congreso de los Diputados celebradas el día 28 de octubre de 1982, Cuadro I, Resumen general, Madrid, 1982.

${ }_{18}^{18}$ Junta Electoral Central, Resumen de los resultados para el Congreso... Cuadro II, Relación de votos correspondientes a cada uno de los partidos... que han obtenido escaños e ídem, Cuadro III, Relación de votos correspondientes a cada uno de los partidos...que no han obtenido escaños, ambos Madrid, 1982

${ }_{19}$ Junta Electoral Central, Elecciones generales del 28 de octubre de 1982. Actas de escrutinio general, Madrid, 1983.

${ }^{20}$ L. López NIETo y M. A. Ruiz DE AzÚa, "La publicación oficial de los resultados electorales del 28 de octubre de 1982", véase nota de investigación en este mismo número de la REIS.

Además de la falta de datos sobre una provincia (Orense), que se suministrarían algunos meses después, los dos autores han puesto de relieve: errores materiales en la suma (total nacional) de votos válidos y en la de las papeletas en blanco; en dieciséis provincias la suma de votos válidos, de papeletas en blanco o nulas no coincide con la cifra de votantes; incluso en dos casos (Almería y Córdoba) los datos de votantes y votos válidos corresponden a los del Senado y no a los del Congreso. Estos son los errores más graves. Errores menores y alguna que otra laguna aparecen en los otros dos Cuadros y en el volumen de las Actas.

Los dos autores se preocupan de subrayar con razón que "las deficiencias en la publicación oficial de los resultados electorales de octubre de 1982... no afectan en modo alguno al valor democrático de los procesos electorales españoles. Son simplemente el resultado de una inadecuada administración electoral. En ningún caso los errores descubiertos comprometen la validez del sufragio, ni implican cambios en la concesión de escaños en cualquiera de las dos cámaras". Es preciso añadir, sin embargo, que provocan problemas de rompecabeza para el que trabaja sobre dichos datos. Aprovecho la ocasión para expresar mi agradecimiento a Miguel Angel RuIz DE Azúa que me ha suministrado gentilmente otros datos oficiales y me ha indicado ulteriores correcciones. Agradezco también a Alberto Spreafico que, trabajando sobre las mismas fuentes, me advirtió de algunos errores míos en los recuentos definitivos. 
do por la diferencia). La escasa atención de las Juntas provinciales hacia los votos de listas menores (así como para las papeletas en blanco o nulas) puede explicarse (pero no justificarse) por el interés predominante en el método d'Hondt ${ }^{21}$ para la asignación de los escaños. La utilización del método d'Hondt puede explicar también el escaso interés por los porcentajes a todos los niveles.

A propósito de porcentajes, los de los cuadros 4 y 6 correspondientes a cada partido los calculé sobre el total de votos válidos: como ha hecho el Instituto Nacional de Estadística para 1979, lo que me ha permitido hacer las comparaciones.

Por desgracia el Ministerio del Interior, en los días sucesivos a las elecciones, suministró los porcentajes para cada partido calculados sobre el total de votantes: son los que recogió la prensa y circularon en los meses sucesivos. Consecuentemente, los porcentajes aquí presentados, tanto a nivel estatal como provincial, son casi siempre superiores a aquéllos aceptados como buenos ${ }^{22}$. Después de este largo pero necesario paréntesis, llegamos al análisis del voto.

La lectura del cuadro 4 permite darnos cuenta inmediatamente de la dimensión del desplazamiento del voto. La suma aritmética de las variaciones (positivas y negativas) de los porcentajes de las distintas listas sobre el total de votos válidos $( \pm 85,8)$ nos da la medida justa del cataclismo. Como ya es sabido, la división por dos de esta suma nos da el índice de inestabili$\operatorname{dad}^{23}$, que resulta ser aquí de 42,9 puntos, un valor muy alto por sí sólo y que sobresale aún más si lo comparamos con el 8,5 de 1979 con respecto a $1977^{24}$. El trasvase de votos ha sido indudablemente muy alto, como con-

${ }^{21}$ Como es sabido la ley d'Hont consiste esencialmente en dividir los votos de cada partido, empezando por el que ha obtenido más votos, por el número de escaños que hay que atribuir en el colegio electoral. Una vez asignados todos los escaños a los partidos más fuertes, el resto y los votos conseguidos por los partidos más débiles no adquieren mayor importancia a los ojos de quien tendría que registrarlos con precisión. Mayor atención existe, sin embargo, donde funciona la proporcional pura con la consiguiente recuperación de los restos en colegios regionales o nacionales.

22 Bàsta un solo ejemplo pequeño: el porcentaje del PSOE no ha sido 46,1 , sino 48,4. Naturalmente, estos valores cambian bastante a menudo también en las provincias, y precisamente para los mayores partidos. Este error se encuentra en la única tabla general publicada en una revista científica, es decir, en F. OLLERo ButLER, "España para el cambio", Revista de Derecho Político, 16, invierno de 1982-83. Los datos provisionales (y porcentajes calculados sobre los votantes) están presentes en un análisis profundo redactado dos semánas después de las elecciones, pero publicado bastante meses después: J. M. Valles, "Las elecciones legislativas del 28 de octubre de 1982: una aproximación de urgencia", en la Revista de Estudios Políticos, 33, mayo-junio 1983, pp. 221-239.

${ }^{23}$ Cf. M. BARbagit et. al., Fluidez electoral y clases sociales en Italia, Bologna, Il Mulino, 1979 , p. 38.

${ }^{24} \mathrm{El}$ valor medio de este índice calculado para trece países europeos en el periodo 1948-1977 es un 8,1 por 100. Cfr. M. N. Penersen, "The Dynamics of European Party Sistems: Changing Patterns of Electoral Volatily", en el European Journal of Political Research, marzo 1979, pp. 1-26. 
firmaban algunos primeros análisis, según los cuales cerca del 46 por 100 de los electores habría cambiado de voto ${ }^{25}$. A este propósito, no hay que dejar de lado el peso de casi tres nuevos millones de votos válidos en comparación con las elecciones del 79 (véase cuadro 4).

El PSOE ha duplicado casi sus votos, superando la cifra de diez millones (10.127.392) y rozando la mayoría absoluta. Mayoría absoluta que ha conseguido en los escaños (véase cuadro 5), pasando de 121 a 202. Con 134 escaños el PSOE se ha asegurado también la mayoría absoluta en el Senado. Un éxito que jamás consiguió ningún partido en la historia española.

Más relevante aparece el éxito de AP que con 5.409.229 votos ha quintuplicado los obtenidos en 1979, superando en porcentajes al PSOE $(+20)$ y ampliando los escaños del Congreso de 9 a 105, además de adjudicarse 54 senadores. El botín de AP, que se ha convertido en la mayor fuerza de la oposición de forma un tanto inesperada, ha sido probablemente la novedad más importante de estas elecciones. No es fácil enjuiciar la aportación de los candidatos del PDP a este éxito: el único dato es el de 16 elegidos que han reconocido pertenecer al PDP, cuyos candidatos se habían visto claramente desfavorecidos a la hora de confeccionar las listas electorales. Más clamorosa de lo previsto fue la caída de UCD, la gran derrotada. Era verdaderamente difícil imaginar que un partido que gobernaba pudiera descender a 1.425.248 votos, perdiendo así 4.866.854 equivalentes a 28,2 puntos en porcentaje. En este naufragio, los votos conquistados (139.148) en las tres provincias vascas, pero en coalición con AP, PDP y PDL, apenas tienen importancia, aunque hayan permitido sentar en el Congreso a dos diputados ucedistas. El grupo parlamentario quedó prácticamente destruido: de los 168 diputados salientes, se reeligieron tan sólo 11. Una docena de ministros quedó fuera, como fuera quedó también el presidente del gobierno, Leopoldo Calvo Sotelo.

La hemorragia de UCD fue hacia la derecha y hacia la izquierda, evidentemente no hacia el centro-izquierda, dado que el partido de Suárez no obtuvo prácticamente provecho alguno. Los 604.293 votos del CDS no han sido pocos, sobre todo en las condiciones en que se afrontaron las elecciones, pero sólo han valido para conseguir dos escaños (uno en la capital y otro en Avila, la provincia del propio Suárez).

El otro gran derrotado ha sido el PCE. Este partido ha perdido 1.093 .796 votos, bastante más de la mitad, descendiendo a la modesta suma de 846.440 (6,8 puntos menos). Su resultado en términos de representación parlamentaria fue dramático: sólo cuatro diputados de los 23 precedentes.

Entre los derrotados destaca, en un segundo plano, el PSA, que ha bajado a 84.474 votos $(0,4)$, perdiendo todos sus escaños. A destacar también

${ }^{25}$ P. Sebastián, "El 46 por 100 de votantes cambió de opción”, en Tiempo, 8 de noviembre de 1982. 


\section{CUADRO 4}

Resultados de las elecciones para el Congreso de los Diputados en 1982 y comparación con las precedentes de 1979

\begin{tabular}{|c|c|c|c|c|c|c|}
\hline & \multicolumn{2}{|c|}{1982} & \multicolumn{2}{|c|}{1979} & \multicolumn{2}{|c|}{ Variaciones 1982-1979 } \\
\hline & Votos & $\%$ & Votos & $\%$ & Votos & $\%$ \\
\hline $\begin{array}{llllllllll}\text { PSOE } & \ldots & \ldots & \ldots & \ldots & \ldots & \ldots & \ldots & \ldots & \ldots\end{array}$ & 10.127.392 & 48,4 & 5.477 .037 & 30,5 & +4.650 .355 & $+17,9$ \\
\hline $\begin{array}{lllllllllll}\mathbf{A P} & \ldots & \ldots & \ldots & \ldots & \ldots & \ldots & \ldots & \ldots & \ldots & \ldots\end{array}$ & 5.409 .229 & 25,9 & 1.070 .721 & 5,9 & +4.338 .508 & $+20,0$ \\
\hline 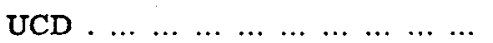 & 1.425 .248 & 6,8 & 6.292 .102 & 35,0 & -4.866 .854 & $-28,2$ \\
\hline AP/UCD $(1) \ldots \ldots c c c c c c$ & 139.148 & 0,6 & - & - & +139.148 & $+0,6$ \\
\hline $\begin{array}{llllllllll}\mathbf{P C E} & \ldots & \ldots & \ldots & \ldots & \ldots & \ldots & \ldots & \ldots & \ldots\end{array}$ & 846.440 & 4,0 & 1.940 .236 & 10,8 & -1.093 .796 & $-6,8$ \\
\hline 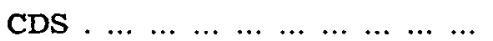 & 604.293 & 2,9 & - & - & $+\quad 604.293$ & $+2,9$ \\
\hline $\begin{array}{llllllllllll} & \mathrm{CiU} & \ldots & \ldots & \ldots & \ldots & \ldots & \ldots & \ldots & \ldots & \ldots & \ldots\end{array}$ & 772.726 & 3,7 & 483.446 & 2,7 & +289.280 & $+1,0$ \\
\hline 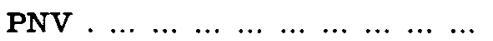 & 395.656 & 1,9 & 275.292 & 1,5 & $+\quad 120.364$ & $+0,4$ \\
\hline $\begin{array}{llllllllllll}\text { нв } & \ldots & \ldots & \ldots & \ldots & \ldots & \ldots & \ldots & \ldots & \ldots & \ldots\end{array}$ & 210.601 & 1,0 & 172.710 & 0,9 & $+\quad 37.891$ & $+0,1$ \\
\hline $\begin{array}{lllllllllll}\mathbf{E R C} & \ldots & \ldots & \ldots & \ldots & \ldots & \ldots & \ldots & \ldots & \ldots\end{array}$ & 138.116 & 0,7 & 123.448 & 0,7 & 14.668 & $=$ \\
\hline $\begin{array}{lllllllllll}\mathbf{E E} & \ldots & \ldots & \ldots & \ldots & \ldots & \ldots & \ldots & \ldots & \ldots & \ldots\end{array}$ & 100.326 & 0,5 & 85.677 & 0,5 & $+\quad 14.649$ & $=$ \\
\hline 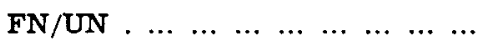 & 108.899 & 0,5 & 379.463 & 2,1 & -270.564 & $-1,6$ \\
\hline $\begin{array}{llllllllll}\mathbf{P S A} & \ldots & \ldots & \ldots & \ldots & \ldots & \ldots & \ldots & \ldots & \ldots\end{array}$ & 84.474 & 0,4 & 325.842 & 1,8 & -241.368 & $-1,4$ \\
\hline $\begin{array}{llllllllll}\operatorname{Otros} & \ldots & \ldots & \ldots & \ldots & \ldots & \ldots & \ldots & \ldots & \ldots\end{array}$ & 554.657 & 2,7 & 1.340 .218 & 7,6 & -785.561 & $-4,9$ \\
\hline Total votos válidos $\ldots \ldots \ldots$ & 20.917 .205 & 100,0 & 17.965.592 & 100,0 & +2.951 .613 & $( \pm 85,8)$ \\
\hline Papeletas en blanco y nulas ... & 506.201 & & 330.226 & & $+\quad 175.975$ & \\
\hline $\begin{array}{llllllllll}\text { Votantes } & \ldots & \ldots & \ldots & \ldots & \ldots & \ldots & \ldots & \ldots\end{array}$ & 21.423.406 & $(79,8 \%)$ & 18.295 .818 & $(68,3 \%)$ & +3.127 .588 & \\
\hline $\begin{array}{llllllll}\text { Electore } & \ldots & \ldots & \ldots & \ldots & \ldots & \ldots & \ldots\end{array}$ & 26.855 .301 & & 26.786 .042 & & $+\quad 69.259$ & \\
\hline
\end{tabular}

(1) Lista unida para las tres provincias vascas (Alava, Guipúzcoa y Vizcaya). 
Fuerza Nueva-Unidad Nacional, representación de aquella derecha que en el aniversario de la muerte de Franco llenaba la Plaza de Oriente con camisas azules y saludos a la romana: la lista de extrema derecha descendió a 108.899 votos (del 2,1 al 0,5 por 100), perdiendo su único diputado, Blas Piñar, que esperaba conseguir el 5 por 100 y cinco diputados. A propósito de la extrema derecha, conviene recordar que la lista del golpista Tejero consiguió poco más de 25.000 votos en toda España (el 0,1 por 100): un resultado ridículo después de tanto ruido.

Las listas nacionalistas se han mantenido tan sólo en el País Vasco y Cataluña. Herri Batasuna (HB) y Euzkadiko Ezkerra (EE) han mejorado ligeramente sus posiciones; en situación estacionaria quedó Esquerra Republicana de Catalunya (ERC). Bastante más significativos han sido los progresos de Convergencia i Unió (772.726 votos; más que el partido de Suárez) y del Partido Nacionalista Vasco, que obtuvo casi 400.000 , a pesar del éxito del PSOE en la región. Son signo de la capacidad de resistencia de fuerzas no estatales moderadas, que probablemente han sido beneficiarias por la destrucción del centro ${ }^{26}$.

No vale la pena reseñar las listas menores. Sin embargo, conviene destacar que los votos asignados al término «otros» han bajado considerablemente, del 7,6 por 100 en 1979 al 2,7 por 100. Por último, hay que evidenciar que sólo el 3,6 por 100 de los votos expresados ha quedado esta vez sin representación parlamentaria (en 1979 fue un 6,7 por 100).

Estos últimos datos pueden considerarse como indicadores de un alto grado de competitividad, con una consiguiente reducción en la dispersión del voto. Son, por lo demás, una prueba adicional de otro fenómeno, la concentración del voto en pocos partidos. El indicador más significativo de esta última tendencia lo proporciona la suma de los porcentajes de los dos partidos mayores: mientras en 1979 esta suma daba un 65,5 por 100 (UCD y PSOE), en 1982 dio un 74,3 por 100 (PSOE y AP).

En lo que respecta a la representación parlamentaria, la concentración del voto en pocos grupos fue naturalmente más fuerte en el Senado. Lo demuestran claramente las columnas del cuadro 5: además de los dos partidos mayores, sólo han quedado en el Senado UCD, CiU y PNV, más dos independientes (tres en 1979); han desaparecido los demás partidos (en 1979 había un senador del PCE y uno de HB). Además, el mecanismo fuerte-

26 "Cataluña y País Vasco - ha escrito un editorialista anónimo con una lucidez que merece citarlo- han sido los únicos ámbitos electorales donde la presencia de partidos nacionalistas moderados, homologables al centrismo democrático, ha bloqueado la bipolarización entre el PSOE y Alianza Popular. Estos resultados y el naufragio del PSA confirman que Cataluña y País Vasco son los únicos territorios donde existen sentimientos nacionalistas enraizados y clases medias -burguesías industriales y comerciales- capaces de apoyar a partidos políticos que combinan el nacionalismo con la moderación" ("Cataluña y el País Vasco", en El País, 2 de noviembre de 1982). 
mente mayoritario del Senado ha favorecido bastante al PSOE, mientras la derecha (AP) y el centro (UCD) se han perjudicado mutuamente.

Afloran con claridad los fenómenos más importantes del sistema partidista: las consecuencias electorales (y no sólo electorales) de la división de las fuerzas moderadas y conservadoras y, en la otra orilla, la capacidad de aglutinación del PSOE. Es lo que abordaré en los parágrafos que siguen.

\section{CUADRO 5}

La distribución de escaños en el Congreso de los Diputados y en el Senado en 1982 y comparación con 1979

\begin{tabular}{|c|c|c|c|c|c|c|}
\hline & \multicolumn{3}{|c|}{$\begin{array}{c}\text { Congreso de los } \\
\text { Diputados }\end{array}$} & \multicolumn{3}{|c|}{ Senado } \\
\hline & 1982 & 1979 & \pm & 1982 & 1979 & \pm \\
\hline $\begin{array}{llllll}\text { PSOE } & \ldots & \ldots & \ldots & \ldots & \ldots\end{array}$ & 202 & 121 & +81 & 134 & 69 & +65 \\
\hline 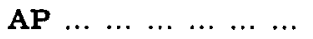 & 105 & 9 & +96 & 54 & 3 & +51 \\
\hline $\mathrm{UCD} \ldots \ldots \ldots \ldots \ldots$ & 11 & 168 & -157 & 4 & 120 & -116 \\
\hline $\operatorname{AP} / \mathbf{U C D} \ldots \ldots \ldots$ & 2 & - & +2 & - & - & - \\
\hline $\begin{array}{llllll}\mathbf{P C E} & \ldots & \ldots & \ldots & \ldots & \ldots \\
\end{array}$ & 4 & 23 & -19 & 一 & 1 & -1 \\
\hline CDS $\ldots \ldots \ldots \ldots$ & 2 & - & +2 & - & 一 & - \\
\hline 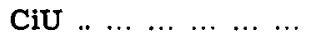 & 12 & 8 & +4 & 7 (1) & 1 & +6 \\
\hline PNV $\ldots \ldots \ldots c c c c c$ & 8 & 7 & +1 & 7 & 8 & - \\
\hline $\begin{array}{llllllll} & \mathrm{HB} & \ldots & \ldots & \ldots & \ldots & \ldots & \ldots\end{array}$ & 2 & 3. & -1 & - & 1 & -1 \\
\hline $\begin{array}{llllllll}\mathbf{E E} & \ldots & \ldots & \ldots & \ldots & \ldots & \ldots\end{array}$ & 1 & 1 & $=$ & - & - & - \\
\hline $\operatorname{ERC} \ldots \ldots \ldots c c c c$ & 1 & 1 & $=$ & - & - & - \\
\hline $\begin{array}{lllllll}P S A & \ldots & \ldots & \ldots & \ldots & \ldots\end{array}$ & - & 5 & -5 & - & - & - \\
\hline $\begin{array}{llllll}\text { Otros } & \ldots & \ldots & \ldots & \ldots & \ldots\end{array}$ & - & 4 & -4 & 2 & $\mathbf{5}$ & -3 \\
\hline Total ... ... ..... & 350 & 350 & & 208 & 208 & \\
\hline
\end{tabular}

(1) En 1982 coalición de UCD, CDC y ERC.

\section{EL VOTO DEL PSOE: EN LA EXPANSION GENERAL SE ACENTUA MAS LA AGREGACION DE LA IZQUIERDA}

Para subrayar la amplitud del éxito socialista empezaré por recordar algunos aspectos meramente estadísticos.

Por primera vez el PSOE ha conseguido escaños en todas las provincias. Ha llegado a ser el primero en 42 de las 52 provincias (en 1979 lo fue en 14), de las restantes AP ha sido primera en siete, el PNV en dos y $\mathrm{CiU}$ en una (véase cuadro 6) ${ }^{27}$. No ha bajado del 25 por 100 de los votos

27 Las provincias donde ha vencido AP se encuentran en Galicia (Lugo, Orense y Pontevedra) y en Castilla-León (Avila, Burgos, Segovia y Soria). El PNV ha quedado primero, naturalmente, en las dos mayores provincias vascas (Guipúzcoa y Vizcaya) y CiU en una catalana (Gerona). 


\section{CUADRO 6}

Porcentajes de los votos conseguidos por los tres partidos mayoritarios en 1979 y 1982 y variaciones (por provincias)

\begin{tabular}{|c|c|c|c|c|c|c|c|c|c|}
\hline & \multicolumn{3}{|c|}{ PSOE } & \multicolumn{3}{|c|}{$A P$} & \multicolumn{3}{|c|}{$U C D$} \\
\hline & 1979 & 1982 & \pm & 1979 & 1982 & \pm & 1979 & 1982 & \pm \\
\hline Alava $\ldots \ldots \ldots c c c$ & 21,4 & 35,5 & $+14,1$ & $(6,2)$ & & & $(25,5)$ & & \\
\hline Albacete $\ldots \ldots \ldots$ & 38,8 & 53,9 & $+15,1$ & 4,9 & 29,0 & $+24,1$ & 39,0 & 8,7 & $-30,3$ \\
\hline Alicante $\ldots \ldots \ldots \ldots$ & 39,5 & 54,3 & $+14,8$ & 5,2 & 29,1 & $+23,9$ & 37,5 & 7,2 & $-30,3$ \\
\hline Almería $\ldots \ldots \ldots \ldots$ & 37,1 & 58,0 & $+20,9$ & 4,4 & 23,3 & $+18,9$ & 44,3 & 11,3 & $-33,0$ \\
\hline Avila $\ldots \ldots \ldots \ldots \ldots$ & 20,1 & 30,7 & $+10,6$ & 6,9 & 33,5 & $+26,6$ & 66,1 & 10,1 & $-56,0$ \\
\hline Badajoz ... . . . . . . . & 37,4 & 57,5 & $+20,1$ & 3,4 & 23,4 & $+20,0$ & 44,7 & 8,4 & $-36,3$ \\
\hline Baleares $\ldots \ldots \ldots$. $\ldots$ & 29,5 & 40,6 & $+11,1$ & 9,2 & 37,9 & $+28,7$ & 49,1 & 10,5 & $-38,6$ \\
\hline Barcelona $\ldots \ldots \ldots$ & 30,4 & 48,6 & $+18,2$ & 3,7 & 14,5 & $+10,8$ & 17,0 & 1,5 & $-15,5$ \\
\hline $\begin{array}{lllll}\text { Burgos } & \ldots & \ldots & \ldots & \ldots\end{array}$ & 23,1 & 37,5 & $+14,4$ & 8,2 & 42,9 & $+34,7$ & 53,2 & 9,7 & $-43,5$ \\
\hline Cáceres $\ldots \ldots \ldots \ldots$ & 38,0 & 52,7 & $+14,7$ & 4,1 & 25,6 & $+21,5$ & 47,4 & 13,3 & $-34,1$ \\
\hline Cádiz ... ... ........ & 30,2 & 63,8 & $+33,6$ & 3,3 & 20,1 & $+16,8$ & 29,5 & 4,7 & $-24,8$ \\
\hline Castellón . ... . . . . . & 35,8 & 50,0 & $+14,2$ & 3,5 & 28,3 & $+24,8$ & 49,5 & 12,8 & $-36,7$ \\
\hline Ciudad Real . ... ... & 39,6 & 54,1 & $+14,5$ & 4,8 & 28,3 & $+23,5$ & 41,6 & 10,5 & $-31,1$ \\
\hline Córdoba ... ... ... ... & 30,2 & 58,1 & $+27,9$ & 5,7 & 21,5 & $+15,8$ & 30,0 & 6,8 & $-23,2$ \\
\hline Coruña (La) . ... ... & 17,9 & 38,4 & $+20,5$ & 11,8 & 35,3 & $+23,5$ & 46,6 & 13,0 & $-33,6$ \\
\hline $\begin{array}{lllll}\text { Cuenca } & \ldots & \ldots & \ldots & \ldots\end{array}$ & 31,6 & 45,2 & $+13,6$ & 6,0 & 32,1 & $+26,1$ & 52,6 & 15,2 & $-37,4$ \\
\hline $\begin{array}{ccccc}\text { Gerona } & \ldots & \ldots & \ldots & \ldots\end{array}$ & 28,1 & 34,2 & $+6,1$ & 3,4 & 13,2 & $+9,8$ & 25,0 & 2,2 & $-22,8$ \\
\hline Granada...$\ldots \ldots$ & 35,8 & 57,9 & $+22,1$ & 4,7 & 24,1 & $+19,4$ & 36,7 & 6,9 & $-29,8$ \\
\hline Guadalajara . ... ... & 23,4 & 38,4 & $+15,0$ & 10,9 & 37,9 & $+27,0$ & 46,5 & 13,5 & $-33,0$ \\
\hline Guipúzcoa $\ldots \ldots \ldots$ & 18,2 & 26,1 & $+7,9$ & $(1,0)$ & & & $(15,4)$ & & \\
\hline $\begin{array}{llllll}\text { Huelva } & \ldots & \ldots & \ldots & \ldots\end{array}$ & 35,5 & 63,4 & $+27,9$ & 3,3 & 20,8 & $+17,5$ & 37,3 & 7,8 & $-29,5$ \\
\hline $\begin{array}{llllll}\text { Huesca } & \ldots & \ldots & \ldots & \ldots\end{array}$ & 34,8 & 47,2 & $+12,4$ & 4,5 & 26,1 & $+21,6$ & 48,1 & 14,8 & $-33,3$ \\
\hline Jaén $\ldots \ldots \ldots \ldots \ldots$ & 41,9 & 57,0 & $+15,1$ & 3,6 & 23,0 & $+19,4$ & 33,8 & 8,9 & $-24,9$ \\
\hline 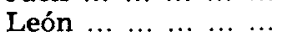 & 27,9 & 45,0 & $+17,1$ & 11,4 & 31,9 & $+20,5$ & 50,4 & 15,6 & $-34,8$ \\
\hline Lérida $\ldots \ldots \ldots \ldots \ldots$ & 25,0 & 35,4 & $+10,4$ & 3,2 & 15,9 & $+12,7$ & 31,8 & 5,7 & $-26,1$ \\
\hline Logroño $\ldots \ldots \ldots \ldots$ & 29,3 & 43,8 & $+14,5$ & 13,9 & 41,8 & $+27,9$ & 48,3 & 7,5 & $-40,8$ \\
\hline 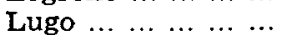 & $\mathbf{1 7 , 5}$ & 28,0 & $+10,5$ & 19,3 & 46,5 & $+27,2$ & 50,2 & 18,2 & $-32,0$ \\
\hline
\end{tabular}




\section{CUADRO 6 (continuación)}

Porcentajes de los votos conseguidos por los tres partidos mayoritarios en 1979 y 1982 y variaciones (por provincias)

\begin{tabular}{|c|c|c|c|c|c|c|c|c|c|}
\hline & \multicolumn{3}{|c|}{ PSOE } & \multicolumn{3}{|c|}{$A P$} & \multicolumn{3}{|c|}{$U C D$} \\
\hline & 1979 & 1982 & \pm & 1979 & 1982 & \pm & 1979 & 1982 & \pm \\
\hline $\begin{array}{llllll}\text { Madrid } & \ldots & \ldots & \ldots & \ldots\end{array}$ & 33,5 & 52,6 & $+19,1$ & 8,6 & 32,5 & $+23,9$ & 33,3 & $\mathbf{3 , 4}$ & $-29,9$ \\
\hline $\begin{array}{llllll}\text { Málaga } & \ldots & \ldots & \ldots & \ldots\end{array}$ & 36,0 & 62,2 & $+26,2$ & 3,9 & 23,4 & $+19,5$ & 29,1 & 3,8 & $-25,3$ \\
\hline $\begin{array}{lllll}\text { Murcia } & \ldots & \ldots & \ldots & \ldots\end{array}$ & 39,3 & 50,9 & $+11,6$ & 5,7 & 35,7 & $+30,0$ & 39,2 & 6,5 & $-32,7$ \\
\hline $\begin{array}{lllll}\text { Navarra } & . . & \ldots & \ldots & \ldots\end{array}$ & 22,0 & 37,9 & $+15,9$ & - & 25,7 & $\begin{array}{r}25,7 \\
+25\end{array}$ & 33,0 & 10,5 & $-22,5$ \\
\hline Orense $\quad \ldots \ldots c c c c$ & 16,2 & 28,4 & $+12,2$ & 18,7 & 35,8 & $+17,1$ & 52,5 & 29,3 & $-23,2$ \\
\hline $\begin{array}{llllll}\text { Oviedo } & \ldots & \ldots & \ldots & \ldots\end{array}$ & 37,4 & 52,4 & $+15,0$ & 8,6 & 28,1 & $+19,5$ & 33,1 & 4,9 & $-28,2$ \\
\hline Palencia ... ....... & 26,2 & 43,0 & $+16,8$ & 9,5 & 39,0 & $+29,5$ & 51,8 & 10,7 & $-41,1$ \\
\hline Palmas (Las) ... ... & 14,5 & 33,2 & $+18,7$ & 3,0 & 29,7 & $+26,7$ & 59,9 & 13,9 & $-\mathbf{4 6 , 0}$ \\
\hline Pontevedra ... ... ... & 17,0 & 30,6 & $+13,6$ & 12,1 & $\mathbf{3 7 , 7}$ & $+25,6$ & 48,4 & 18,6 & $-29,8$ \\
\hline Salamanca $\ldots \ldots \ldots$ & 26,6 & 46,3 & $+19,7$ & 7,8 & 29,9 & $+22,1$ & 53,8 & 13,8 & $-40,0$ \\
\hline S. C. de Tenerife ... & 21,8 & 41,0 & $+19,2$ & 4,6 & 24,6 & $+20,0$ & 56,9 & 19,3 & $-31,6$ \\
\hline Santander $\ldots \ldots \ldots$ & 30,4 & 45,5 & $+15,1$ & 10,1 & 39,1 & $+29,0$ & 42,0 & 5,4 & $-36,6$ \\
\hline Segovia $\ldots \ldots \ldots \ldots$ & 23,2 & $\mathbf{3 7 , 5}$ & $+14,3$ & 6,6 & 38,7 & $+32,1$ & 59,8 & 10,6 & $-49,2$ \\
\hline $\begin{array}{lllll}\text { Sevilla } & \ldots & \ldots & \ldots & \ldots\end{array}$ & 29,4 & 62,2 & $+32,8$ & 4,7 & 22,0 & $+17,3$ & 27,6 & 3,8 & $-23,8$ \\
\hline $\begin{array}{llllll}\text { Soria } & \ldots & \ldots & \ldots & \ldots & \ldots\end{array}$ & 25,8 & 35,8 & $+10,0$ & 10,1 & 37,7 & $+27,6$ & 57,8 & 18,9 & $-38,9$ \\
\hline Tarragona $\ldots \ldots \ldots$ & 28,9 & 42,2 & $+13,3$ & 4,1 & 17,9 & $+13,8$ & 28,3 & 4,4 & $-23,9$ \\
\hline Teruel $\ldots \ldots \ldots \ldots$ & 27,2 & 41,2 & $+14,4$ & 8,1 & 33,7 & $+29,6$ & 55,8 & 16,7 & -39.1 \\
\hline Toledo $\ldots \ldots \ldots \ldots$ & 32,2 & 47,2 & $+15,0$ & 5,6 & 33,6 & $+28,0$ & 41,7 & 9,7 & $-32,0$ \\
\hline Valencia $\ldots \ldots \ldots \ldots$ & 36,7 & 53,3 & $+16,6$ & 4,4 & 29,4 & $+25,0$ & 33,9 & 4,4 & $-29,5$ \\
\hline Valladolid $\ldots . . . \quad \ldots$ & 30,5 & 51,6 & $+21,1$ & 8,4 & 31,5 & $+23,1$ & 39,8 & 7,4 & $-32,4$ \\
\hline $\begin{array}{llllll} & \text { Vizcaya } & \ldots & \ldots & \ldots & \ldots\end{array}$ & 19,1 & 29,8 & $+10,7$ & $(4,2)$ & & & $(16,0)$ & & \\
\hline Zamora $\ldots \ldots \ldots$ & 22,7 & 36,4 & $+13,7$ & 16,4 & 36,2 & $+19,8$ & 50,9 & 18,8 & $-32,1$ \\
\hline Zaragoza . ... ... ... & 26,8 & 51,6 & $+24,8$ & 5,4 & 31,7 & $+26,3$ & 36,3 & 6,9 & $-29,4$ \\
\hline $\begin{array}{ccccc}\text { Ceuta } & \ldots & \ldots & \ldots & \ldots\end{array}$ & 35,5 & 45,4 & $+9,9$ & 7,9 & 29,8 & $+21,9$ & 52,1 & 7,2 & $-44,9$ \\
\hline Melilla ... ... ... ... & 21,5 & 49,3 & $+27,8$ & 4,9 & 26,6 & $+21,7$ & 51,8 & 14,8 & $-37,0$ \\
\hline TOTAL $\ldots \ldots \ldots$ & $\mathbf{3 0 , 5}$ & 48,4 & $+17,9$ & $\mathbf{5 , 9}$ & 25,9 & $+20,0$ & 35,0 & 6,8 & $-28,2$ \\
\hline
\end{tabular}


en ninguna provincia, mientras superaba el 50 por 100 en 20 y el 60 por 100 en las cuatro de Andalucía occidental (véase gráfico 1).

El PSOE ha penetrado en las provincias tradicionalmente moderadas de las dos Castillas (véase, en particular, los datos de Salamanca y Valladolid) y de Aragón (Zaragoza), coronando un proceso que había empezado ya en 1979. Ha conseguido ser el primer partido incluso en una provincia de Galicia (La Coruña); ha ganado Ceuta y Melilla; ha avanzado en el País Vasco y Cataluña.

El cuadro 6 nos demuestra la amplitud de los saltos en los porcentajes por provincias entre las dos elecciones, naturalmente todos positivos para el PSOE. Se pasa de un mínimo de puntos 6,1 (Gerona) a un máximo de 33,6 (Cádiz). Después del de Cádiz, los mayores saltos porcentuales están también en Andalucía (con la única excepción de Jaén, que en 1979 había sido ya la provincia con mayor porcentaje de votos socialistas). Entre los avances más importantes para el PSOE destacan luego el $+24,8$ de Zaragoza, el $+21,1$ de Valladolid, el $+20,5$ de La Coruña y el $+19,1$ de Madrid (sin tener demasiado en cuenta el $+27,8$ de Melilla).

Desde un punto de vista territorial, la expansión del PSOE adquiere así un carácter general y suficientemente uniforme. Es preciso ahora preguntarse de dónde provienen los nuevos 4.600 .000 votos obtenidos en 1982 con respecto a 1979.

Algunas hipótesis formuladas al día siguiente de la consulta electoral se inclinaban a atribuir al PSOE sólo una parte (cerca de un millón) de los votos perdidos por UCD, mientras otro millón vendría del PCE y casi dos millones de nuevos electores y de aquellos que han vuelto a las urnas; quedarían así 600.000 votos que pueden atribuirse a anteriores electores de listas nacionalistas o de extrema izquierda.

Después de una reflexión más sosegada y con los datos definitivos en la mano, estas hipótesis me parecen plenamente aceptables. Trataré de corroborarlas con alguna consideración de carácter general y recurriendo a algún dato significativo.

En primer lugar, es plausible pensar que sólo una parte de ex centristas se ha inclinado hacia el PSOE: para ser exactos una cuarta parte. Es seguro que, en todo el país y sin exceptuar ningún territorio, muchos ex electores centristas han votado socialismo. Pero el avance del PSOE en las provincias conservadoras, que pareció tan clamoroso, debería reconsiderarse en su justa medida, teniendo en cuenta que esas provincias son las de menor censo electoral. Es verdad que aquí los beneficios del PSOE han sido decisivos para conquistar mayorías relativas y muchos escaños nuevos. Sin embargo, los éxitos porcentuales y los nuevos diputados (y senadores) resultan también, y sobre todo, de otras dos razones: la división entre UCD y AP y el nuevo abstencionismo. La división del electorado conservador ha perjudicado, más que en otra cuestión (precisamente por su mayor presencia) las dos listas 
de centro y derecha (he hablado ya de este fenómeno general y volveré a él definitivamente en el próximo apartado).

La división, por lo demás, ha debido desmoralizar a parte de ese mismo electorado conservador, manteniéndolo lejos de las urnas: se puede apreciar cómo, en contra de la tendencia general hacia una mayor afluencia, se registran nuevas abstenciones en Castilla-La Mancha, Baleares y Logroño, precisamente allí donde el PSOE, inesperadamente, ha suplantado a los partidos conservadores. Añádase, por último, que todos estos fenómenos se han visto agigantados por el hecho de que en provincias pequeñas y despobladas bastan pocos votos absolutos para producir desplazamientos y cambios importantes. Por tanto, es bastante seguro que el PSOE haya obtenido muchos más votos del electorado potencialmente de izquierdas que de la derecha. Veámoslo detenidamente.

El mapa 1, que nos demuestra claramente cuál ha sido la fuerza electoral del PSOE en toda España, nos indica también, de un modo inmediato, la continuidad de la implantación electoral socialista. La gran base del consenso para el PSOE se encuentra todavía en las regiones del Sur y del Levante (con una extensión a modo de mancha de aceite hacia Extremadura y CastillaLa Mancha): son las regiones donde el PSOE cuenta con más profundas

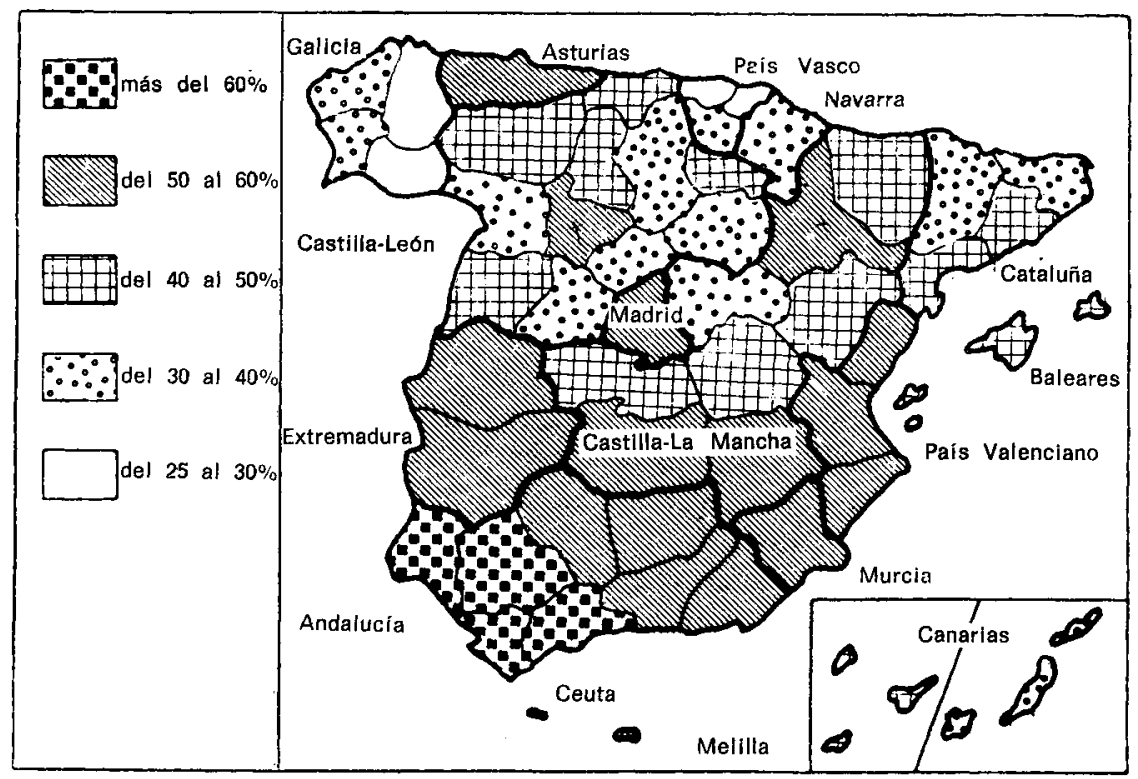

MaPA 1.-Elecciones para el Congreso de Diputados en 1982. Resultados del PSOE por provincias (porcentajes) 
y antiguas raíces ${ }^{28}$. Sin embargo, no es éste el punto que quiero poner aquí de relieve.

Es preciso en cambio recordar que las regiones del Sur y del Levante son aquellas en las que la izquierda en su conjunto ha sido siempre dominante. Esto significa que el PSOE ha progresado precisamente donde era más fuerte, pero ha avanzado más allí donde el votante era de izquierda y se habían orientado anteriormente hacia otras opciones. En la España roja (una expresión, dicho sea de pasada, utilizada a menudo en la prensa de derechas) el PSOE ha absorbido tanto electores del PCE, como de listas de extrema izquierda y listas nacionalistas. E1 hundimiento del PSA en Andalucía, iniciado en las autonómicas de mayo y acentuado ya con la crisis del liderazgo de Rojas Marcos, ha contribuido a este éxito. Como también ha contribuido, tanto en Andalucía como en el País Valenciano, el bajón del PCE.

Hay más datos que confirman los flujos hacia el PSOE en el interior de la izquierda. Los de Madrid y Barcelona (procedentes de votantes del PCE); los de Galicia y Canarias (procedentes de listas nacionalistas de extrema izquierda $)^{29}$. Los de las grandes ciudades revelan un descenso considerable de votos en los grupos extraparlamentarios de izquierdas ${ }^{30}$ : también para sus seguidores el PSOE se convirtió en polo de atracción ${ }^{31}$.

Los ejemplos del cuadro 7 confirman que el PSOE ha ganado mucho más de la izquierda que del centro. Tres de los grupos formados por las nueve provincias que he elegido se encuentran en regiones muy distintas entre sí en cultura política y estructuras socioeconómicas: Galicia (La Coruña y Lugo), Castilla-León (Salamanca y León) y Andalucía (Cádiz y Sevilla). Las otras tres provincias tienen como capital un área metropolitana. Pues bien, en todas estas provincias las pérdidas de UCD no compensan las ganancias del PSOE y AP. Si admitimos que AP ha recogido todos los votos que anteriormente eran de UCD, se puede decir que el PSOE los ha conseguido en gran medida en otro sitio, precisamente en la izquierda.

${ }_{28}$ Sobre este punto puede consultarse $\mathrm{mi}$ "Le risorse e i ritardi del Partido Socialista Obrero Español", en Il Mulino, 282-283, julio-octubre de 1982, en particular pp. 674-683.

${ }^{29}$ Por ejemplo, la Unión del Pueblo Canario, coalición de partidos nacionalistas de izquierda, ha bajado de 58.953 votos a 35.013 , perdiendo así el diputado que había obtenido en 1979.

30 También para estas listas menores basta con un ejemplo: la Liga Comunista Revolucionaria (LCR) ha caído de 37.087 a 1.053 . Se ha calculado que las listas de extrema izquierda de implantación estatal han pasado del 2,9 por 100 de 1979 al 0,9 (J. M. Valles, Las elecciones legislativas del 28 de octubre de 1982..., cit. páginas 229-230).

${ }^{31}$ Sobre la crisis de los grupos de extrema izquierda y sobre la reconversión de sus seguidores "a la política como arte de lo posible y al socialismo como proceso de reformismo radical", ver L. PARAMIo, "El final del desencanto", en Leviatán, 9, otoño 1982, en particular pp. 26-31.

Es inútil añadir que las únicas listas de extrema izquierda que han conseguido estar presentes de nuevo en la arena electoral han sido las del nacionalismo vasco, Euskadiko Ezkerra y Herri Batasuna. 


\section{CUADRO 7}

Saldo de los porcentajes de los votos conseguidos por los tres mayores partidos en algunas provincias

\begin{tabular}{|c|c|c|c|}
\hline Provincias & PSOE & $A P$ & $U C D$ \\
\hline $\begin{array}{lllllllll}\text { La Coruña } & \ldots & \ldots & \ldots & \ldots & \ldots & \ldots \\
\text { Lugo } & \ldots & \ldots & \ldots & \ldots & \ldots & \ldots & \ldots & \ldots\end{array}$ & $\begin{array}{l}20,5 \\
10,5\end{array}$ & $\begin{array}{l}23,5 \\
27,2\end{array}$ & $\begin{array}{l}-33,6 \\
-32,0\end{array}$ \\
\hline $\begin{array}{llllllll}\text { Salamanca } & \ldots & \ldots & \ldots & \ldots & \ldots & \ldots \\
\text { León } & \ldots & \ldots & \ldots & \ldots & \ldots & \ldots & \ldots \\
\end{array}$ & $\begin{array}{l}19,7 \\
17,1\end{array}$ & $\begin{array}{l}22,1 \\
20,5\end{array}$ & $\begin{array}{l}-40,0 \\
-34,8\end{array}$ \\
\hline $\begin{array}{lllllllll}\text { Cádiz } & \ldots & \ldots & \ldots & \ldots & \ldots & \ldots & \ldots & \ldots \\
\text { Sevilla } & \ldots & \ldots & \ldots & \ldots & \ldots & \ldots & \ldots\end{array}$ & $\begin{array}{l}33,6 \\
32,8\end{array}$ & $\begin{array}{l}16,8 \\
17,3\end{array}$ & $\begin{array}{l}-24,8 \\
-23,8\end{array}$ \\
\hline $\begin{array}{llllllll}\text { Madrid } & \ldots & \ldots & \ldots & \ldots & \ldots & \ldots & \ldots \\
\text { Barcelona } & \ldots & \ldots & \ldots & \ldots & \ldots & \ldots & \ldots \\
\text { Zaragoza } & \ldots & \ldots & \ldots & \ldots & \ldots & \ldots & \ldots\end{array}$ & $\begin{array}{l}19,1 \\
18,2 \\
24,8\end{array}$ & $\begin{array}{l}23,9 \\
10,8 \\
26,3\end{array}$ & $\begin{array}{r}-29,9 \\
-15,5 \\
-\quad 2,4\end{array}$ \\
\hline
\end{tabular}

La convergencia del electorado de izquierdas en el PSOE ha sido condicionada por sus crecientes expectativas de triunfo, como ya he dicho al principio. El voto útil, del que tanto se había hablado, ha funcionado claramente, desecando los canales paralelos a favor de la arrolladora corriente socialista y reestructurando bruscamente el voto de izquierda ${ }^{32}$.

La expectativa del «cambio» ha funcionado además para un electorado que había desertado de las urnas en 1979. He dicho antes que las cifras sobre la participación electoral deben considerarse con cautela y que no puede establecerse el aumento exacto. No pueden existir dudas de que ha habido un aumento, como no debería de existir dudas tampoco de que los antiguos abstencionistas han optado por el PSOE. En 1979 había sido principalmente un electorado socialista el que desilusionado se abstuvo: la relación entre abstencionismo y pérdidas en el PSOE era clara, por ejemplo, en el País Vasco

32 El mayor afectado ha sido, naturalmente, el PCE. Santiago Carrillo había avisado durante la campaña electoral del peligro del voto útil y lo ha repetido para explicar y justificar la derrota sufrida en las urnas. Ciertamente, el voto comunista se ha trasladado al PSOE masivamente, visto que los prosoviéticos han conseguido sólo un puñado de votos; para ser precisos 47.429 el Partit dels Comunistes de Catalunya y apenas 17.477 el Partido Comunista Obrero Español de Lister.

He hablado ya de la crisis interna del PCE y de las medidas disciplinarias que rompieron el partido. No hay aquí espacio para profundizar en el análisis de una derrota electoral (grave de todas formas y gravísima en Cataluña). Basta recordar algunas de las causas posibles que Carrillo no podía exponer públicamente. Han existido causas con repercusiones negativas, como la ambigüedad ideológica (entre tercerinternacionalismo y eurocomunismo) y la estrategia (apertura a UCD, desplazando al PSOE, redescubriendo a última hora la unidad de la izquierda). Las ha habido también con repercusiones positivas, es decir, favoreciendo al PSOE, como la mayor credibilidad de este último con una oferta electoral casi idéntica, la mayor juventud de los dirigentes, estar prácticamente a un paso del poder. 
y Barcelona; igualmente clara resultó en 1982 la relación entre aumento de la participación y crecimiento del PSOE.

Nos queda por decir, por último, que es muy probable que el PSOE haya incidido sobre las nuevas generaciones de electores. A este respecto no hay datos, pero ha sido opinión generalizada que los más jóvenes han acudido esta vez en masa a las urnas, contradiciendo la propensión a la abstención atribuida a sus coetáneos cuatro años atrás. También ellos, contribuyendo al aumento de votantes, han demostrado interesarse por la expectativa de «cambio» y han seguido la llamada del «voto útil».

Para concluir, se puede decir esquemáticamente del PSOE que: a) se ha beneficiado del crecimiento en la participación; b) ha conseguido apoderarse de casi todo el electorado de izquierdas; c) ha atraído sólo una parte del electorado centrista; d) su avance se ha difundido en todo el territorio nacional, pero de un modo menos homogéneo de lo que pueda parecer en una rápida lectura de los porcentajes y del número de escaños; e) su expansión ha sido más contenida particularmente en dos regiones de fuerte tradición autonomista, el País Vasco y Cataluña.

Geográficamente, pues, se puede, una vez más, constatar que el PSOE es fuerte e imbatible en el Centro-Sur, mientras los éxitos en la zona CentroNorte son limitados y relativamente estables. Precisamente por ello la España del Centro-Norte queda como punto neurálgico en futuras elecciones, como lo confirma el voto del centro y de la derecha que ahora voy a analizar.

\section{EL VOTO CONSERVADOR}

Trataré, en primer lugar, de los efectos negativos que en 1982 produjo el sistema electoral sobre las listas del bando centro-derecha. El sistema electoral se concibió en 1977 con el propósito de favorecer a las listas mayoritarias y, entre ellas, a la lista conservadora -es decir, la coalición que se estaba constituyendo alrededor de Adolfo Suárez y el gobierno artífice de la transición a una democracia competitiva, coalición de la que surgió UCD-. Es evidente que la desproporción entre votos y escaños es más alta en las provincias pequeñas $\mathrm{y} / \mathrm{o}$ menos pobladas $\mathrm{y}$, especialmente, en las castellanas, que son asimismo las más conservadoras: de hecho UCD obtuvo en ellas una prima en escaños tanto en 1977 como en 1979. Además, en 1977 se daba por descontado que, a nivel nacional, frente a un solo gran partido moderado, la izquierda se mantendría dividida entre PSOE y PCE.

En 1982, sin embargo, mientras en la izquierda el PSOE se presentaba como único eje importante, fue precisamente el bando conservador el que se presentó fraccionado. Ya he dicho que esta división ha tenido consecuencias: daré ahora la medida de ello de un modo más preciso.

Con el 48,4 por 100 de los votos el PSOE ha obtenido el 57,7 por 100 
de los escaños del Congreso, con un saldo a favor de $+9,3$ puntos en el porcentaje, mientras el PCE ha sufrido una penalización considerable, $-2,9$ puntos, como se puede apreciar en el cuadro 8 . En el otro bando, AP se ha beneficiado del mecanismo electoral, pero en medida menor que el PSOE $(+4,1$ es el saldo entre el porcentaje de sus votos y el de los escaños, como puede verse en el cuadro); al mismo tiempo se ha penalizado duramente a UCD $(-3,7)$ y todavía más, en proporción, el CDS $(-2,3)$. Tan sólo los partidos nacionalistas vasco y catalán han conseguido møntener casi una paridad entre votos y escaños, lo que es normal, dada su sólida implantación en zonas específicas.

\section{CUADRO 8}

Porcentajes de votos y escaños conseguidos por los mayores partidos $y$ diferencias

\begin{tabular}{|c|c|c|c|}
\hline Partidos & $\%$ votos & $\%$ escaños & \pm \\
\hline PSOE $\ldots \ldots \ldots \ldots \ldots \ldots$ & 48,4 & 57,7 & $+9,3$ \\
\hline $\begin{array}{llllllllll}\mathbf{A P} & \ldots & \ldots & \ldots & \ldots & \ldots & \ldots & \ldots & \ldots & \ldots\end{array}$ & 25,9 & 30,0 & $+4,1$ \\
\hline $\begin{array}{llllllllll}\mathrm{UCD} & \ldots & \ldots & \ldots & \ldots & \ldots & \ldots & \ldots & \ldots\end{array}$ & 6,8 & 3,1 & $-3,7$ \\
\hline $\begin{array}{lllllllllll} & P C E & \ldots & \ldots & \ldots & \ldots & \ldots & \ldots & \ldots & \ldots\end{array}$ & 4,0 & 1,1 & $-2,9$ \\
\hline 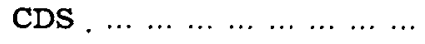 & 2,9 & 0,6 & $-2,3$ \\
\hline $\begin{array}{lllllllllll} & \mathbf{C i U} & \ldots & \ldots & \ldots & \ldots & \ldots & \ldots & \ldots & \ldots & \ldots\end{array}$ & 3,7 & 3,4 & $-0,3$ \\
\hline 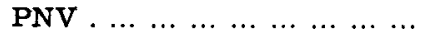 & 1,9 & 2,3 & $+0,4$ \\
\hline
\end{tabular}

A pesar de que la extrema izquierda desapareciera del Congreso, el ala conservadora ha sufrido una penalización en escaños precisamente por su división. Además, puede añadirse un efecto psicológico que, como ya he indicado, ha desmoralizado al elector moderado, induciéndolo a la abstención o incluso a votar socialismo.

Repito, una vez más, que los dos efectos, el cuantitativo y el psicológico, han incidido más en las zonas tradicionalmente conservadoras. El centroderecha ha perdido un buen número de escaños en las dos Castillas, Galicia y Aragón: cuanto más grande sea su fuerza de conjunto, más graves resultan las consecuencias de su división.

Tenían razón los dirigentes de AP para lamentarse, el día después de las elecciones, de que UCD rechazara en su día la propuesta de alianza: el centro-derecha no habría ganado, como alguno de aquellos dirigentes no dejaba de repetir, pero la derrota habría tenido proporciones distintas.

En el fondo, UCD ha conseguido conservar casi un millón y medio de votor. Su caída ha sido más clamorosa porque, a causa del mecanismo del sistema electoral, ha conseguido sólo 11 diputados (de los 40 que L. La- 
villa había prometido la víspera), perdiendo casi por completo su grupo dirigente ${ }^{33}$.

En lo que concierne a sus resultados en distintos niveles, UCD ha desaparecido casi por completo en Andalucía y Cataluña, en Barcelona y en Madrid (en la capital, casi simbólicamente, el segundo de sus listas y primero de los no elegidos, era el presidente del anterior gobierno). Ha conseguido una cota máxima de 29,3 por 100 en Orense, pero no ha alcanzado en ninguna otra provincia el 20 por 100 . Ha registrado los descensos más importantes precisamente donde antes era más fuerte: $-49,2$ en Segovia, -46 en Las Palmas, $-43,5$ en Burgos, hasta llegar al -56 en Avila, caso particular que más adelante explicaré (véase cuadro 6 ). Ha conseguido escaños en Galicia y en las pocas provincias donde los azules, es decir, sus elementos más ligados al último período franquista y a posiciones de poder, estaban mejor representados (a destacar el caso de Martín Villa en León).

De los cuatro millones y pico conseguidos por AP ya he hablado antes. Como también he indicado, al analizar las estadísticas, que AP ha sido el primer partido en siete provincias. Añadiré también que ha quedado segundo en todas las demás, a excepción de las catalanas y las vascas; ha conseguido escaños en todas salvo en Ceuta y Melilla (en el País Vasco aliada con UCD y PDL, además del PDP); ha superado el 40 por 100 en Lugo, Logroño y Burgos, quedando, eso sí, lejos de su media nacional en bastantes provincias (véase cuadro 6). Los mejores resultados los ha conseguido al norte del Tajo.

El flujo de votos hacia AP puede estimarse de la siguiente manera: casi tres millones provenientes de UCD, más de medio millón de nuevos votantes y el resto de Fuerza Nueva y de dos partidos sin representación, el Partido Regionalista de Aragón y la Unión del Pueblo Navarro. Los factores que han influido a favor de AP han sido, evidentemente, la tensión preelectoral y la mayor participación, el temor a una avalancha socialista y la necesidad del «voto útil» para la derecha.

Gracias a este éxito AP se ha perfilado claramente como segundo partido del país, aunque sin llegar a los niveles alcanzados por el PSOE en las dos elecciones precedentes.

El mapa 2 es la representación gráfica de los saldos, todos positivos, de los porcentajes de AP provincia por provincia. Puede advertirse cómo los aumentos más notables han sido, aparte de Murcia, los de las provincias castellanas que rodean a Madrid.

Es en estas provincias rurales y conservadoras donde AP ha crecido más, mientras que, aunque haya hecho progresos, se ha detenido allí donde el

${ }^{33}$ No han sido reelegidos, entre otros, además del presidente del Gobierno, Leopoldo Calvo Sotelo, el secretario general, Iñigo Cavero; el presidente de la Asamblea parlamentaria del Consejo de Europa, José María de Areílza; el ex vicepresidente del Senado, Cecilio Valverde, y los ex ministros, Soledad Becerril, Rafael Arias Salgado, Juan José Rosón, José Pedro Pérez Llorca, Ignacio Camuñas y otros. 


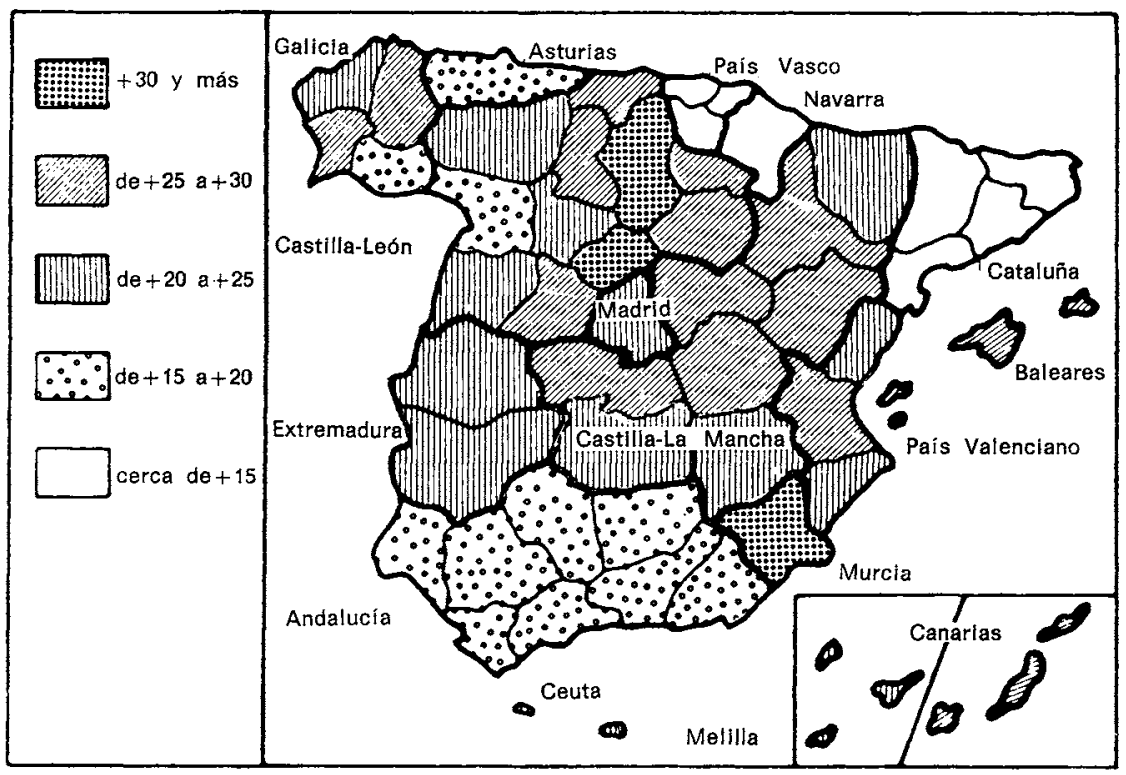

Mapa 2.-Variaciones entre los porcentajes de votos de AP/PDP en 1982 $y$ los de AP (CD) en 1979 por provincia

PSOE estaba más implantado - véanse los reducidos avances en Andalucía, a pesar del desastre de UCD en la zona-. En los progresos electorales de AP hay una continuidad geográfica que salta a la vista y nos revela cuáles son las provincias-clave en el ámbito de lo que antes he llamado «zona neurálgica» de las futuras elecciones. Aquí volverá a jugarse el encuentro decisivo en unas nuevas elecciones - si no en 1986, quizá en 1990-.

Que AP haya suplantado a UCD, absorbiendo con regularidad su electorado, está claramente confirmado por la relación entre sus progresos y las pérdidas del ex partido del gobierno, provincia por provincia. El gráfico 1 muestra con toda evidencia una relación lineal en 48 provincias (las siglas son las de las matrículas automobilísticas) ${ }^{34}$.

Puede observarse cómo todos los puntos del gráfico se sitúan por debajo de la diagonal, demostrando que las pérdidas de UCD han sido en todas partes superiores a las ganancias de AP. El conjunto de puntos tiende más tarde a situarse a lo largo de la recta de regresión, con una sola excepción: se trata de la provincia de Avila, donde una parte de la pérdida récord de UCD ( -56 , como ya había indicado) ha recaído, excepcionalmente, a favor del CDS de Suárez, que ha alcanzado en «su» colegio-el 22,5 por 100 de los votọs. Los grupos de provincias aisladas con dos líneas cerradas son, res-

${ }^{34}$ Quedan excluidas las tres provincias vascas donde los dos partidos se han presentado unidos, y Navarra donde AP no se presentó en 1979. 
pectivamente, las andaluzas (señaladas con una $\mathrm{A}$ ) y las catalanas (con una $\mathrm{C}$ ): demuestran un comportamiento homogéneo a nivel regional.

El cálculo del coeficiente de correlación basado en los 48 casos ha dado como resultado el valor de $-0,69$; mientras, si se descarta el caso anómalo de Avila, el valor sube hasta un 0,72 .

Las cifras hasta ahora expuestas deben considerarse como siempre con cautela. Es difícil, sin embargo, negar que gran parte de los votos de electores ucedistas en toda España hayan recaído en AP. Un electorado que había apoyado anteriormente la opción de centro, se ha refugiado en la derecha ante el «peligro» socialista.

No es fácil predecir las implicaciones de esta recomposición de la derecha electoral cara a la evolución del sistema político. De todos modos lo intentaré a continuación.

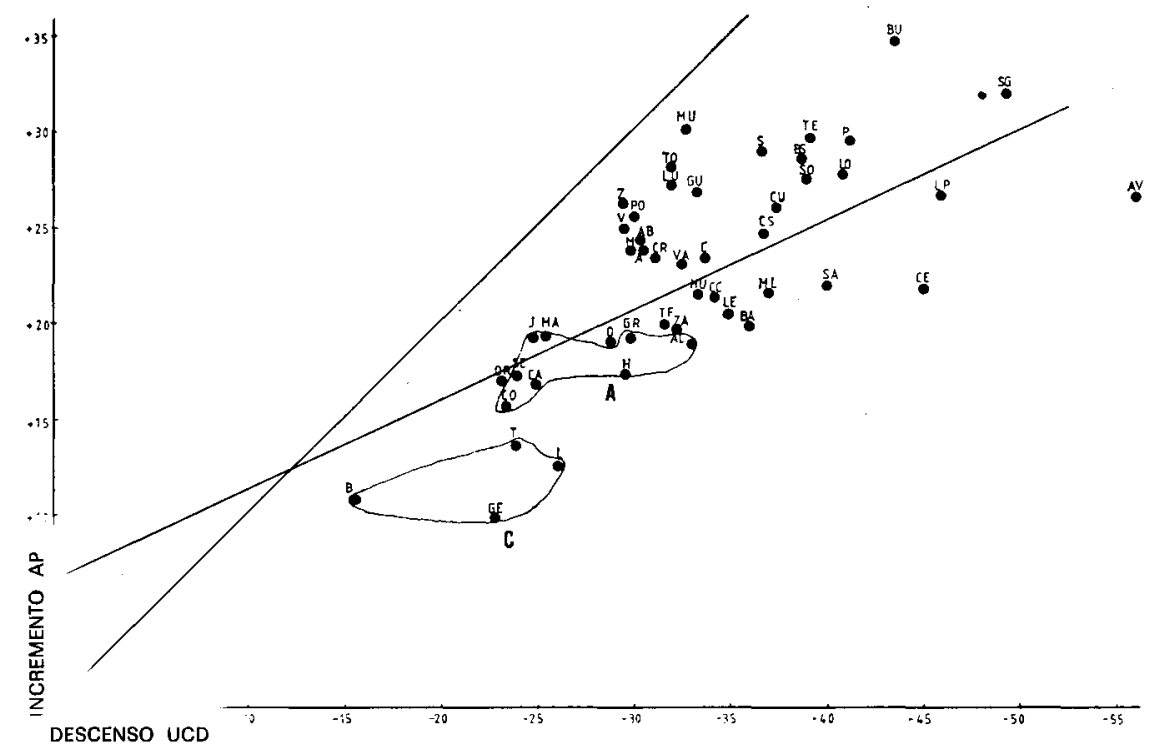

GRÁrico 1.--Incrementos de AP y descensos de UCD 1979-1982 (variaciones de los porcentajes en los votos por provincia)

\section{DINAMICA DEL SISTEMA PARTIDISTA Y CONSOLIDACION DE LA DEMOCRACIA}

No pretendo detenerme mucho en problemas sistémicos en este análisis de comportamiento electoral. Sin embargo, tras resultados tan sorprendentes, me parece oportuno hacer, en las últimas páginas, alguna reflexión acerca de la evolución del sistema de partidos y de las perspectivas del sistema político. 
El cataclismo electoral del 28 de octubre replantea cuestiones y categorías interpretativas ya discutidas en el caso español y abre nuevos problemas. Pienso que el discurso debe plantearse en tres ámbitos distintos: las relaciones de fuerza parlamentarias, las contraposiciones en la sociedad civil y el sistema de partidos.

Las resultados han provocado una nueva concentración de la representa. ción parlamentaria. En 1977 los dos partidos mayores (UCD y PSOE) consiguieron juntos el 63,8 por 100 de los votos; en 1979 los mismos llegaron al 65,5 por 100. En 1982 la suma de los porcentajes del PSOE y AP alcanzó un 74,3 por 100 . No sólo los grupos menores, sino también los intermedios, parecen estar a punto de quedar fuera de la escena política, a excepción del PNV y CiU.

Entre las dos mayores fuerzas políticas ha aumentado también la polarización, entendida como distancia ideológica. Si el PSOE ha mostrado marcados signos de moderación, convergiendo hacia el centro, ahora tiene delante un antagonista mucho más distante de lo que antes podía estar UCD.

Habrá que ver si esta polarización tiende a moderarse, pero se trata también de preguntarse con lucidez si no refleja ya una radicalización en la sociedad civil. La perspectiva de un gobierno socialista ha movilizado un electorado al que asustaba elegir el bando más intransigente. Cabe preguntarse entonces si este electorado es conservador, pero dispuesto a mantenerse fiel a las instituciones y a realizar una oposición leal, o si por el contrario se inclina a nostalgias del régimen autoritario. Los electores moderados que han votado al PSOE esta vez, puede decirse que están plenamente integrados en la monarquía parlamentaria; sin embargo, no puede decirse lo mismo de los que han votado AP. Precisamente AP ha demostrado además saber integrar facciones de extrema derecha, y actitudes marcadamente franquistas.

Es por tanto lógico alimentar dudas sobre la plena integración en la democracia competitiva del polo electoral que se ha formado a la derecha. En la mejor de las hipótesis puede definirse este polo heterogéneo y contradictorio como más sensible a requerimientos autoritarios de lo que anteriormente estuvo el precedente polo centrista. El principal problema español se configura, una vez más, en la formación de un bloque electoral y social que sea conservador y democrático al mismo tiempo. Esto al nivel de sociedad civil.

Al nivel de partidos, AP representa las mismas ambigüedades y suscita las mismas sospechas, siendo así coherente expresión de la base social que la mantiene. En AP coexisten conservadores de fe democrática y resquicios de la derecha más franquista y antiparlamentaria. Los primeros sostienen que su partido representa la derecha democrática, moderada, «europea»: esto es más bien un objetivo que una realidad actual. El partido ha modificado indudablemente su imagen, votando la Constitución, adhiriéndose a manifestaciones antigolpistas, abriéndose a una alianza con el PDP. Sin embargo, el 
camino que debe recorrer hasta su verdadera «modernización», mejor dicho «civilización», como dicen en España, es todavía bastante largo.

Utilizando una conocida clasificación, podría definirlo como un partido en la fase de semiaceptación del sistema. AP es, por tanto, todavía una duda: puede desempeñar la función histórica de integrar en el sistema sectores ya hostiles, pero puede también seguir solicitando una derecha «pura y dura».

Las ambigüedades del partido están personificadas enteramente en su líder, Manuel Fraga. Fraga ha limpiado AP de los personajes más rudos y comprometidos $\mathrm{y}$, sin embargo, él mismo ha seguido escuchando a las facciones más extremistas, militares incluidos. También él busca una imagen democrática, poco afín a su temperamento y sobre todo poco conciliable con su pasado de ministro del régimen. Durante la campaña electoral ha enseñado dos caras distintas según el auditorio y las circunstancias (por ejemplo, al declarar una vez que entendía a los golpistas, y pidiendo otra la pena de muerte para ellos). Frente a los tonos moderados de los socialistas, los suyos parecían todavía rígidos $\mathrm{e}$ intolerantes.

Tras el resultado electoral, prometió una leal oposición parlamentaria, anunciando con anticipación su alternativa frente a lo que, según él, será el inevitable fracaso del gobierno socialista. Coherente con su preferencia por el mecanismo anglosajón de la alternancia, ha demostrado su satisfacción por el hecho de que las dos grandes fuerzas políticas se encuentren cara a cara (olvidando las minorías nacionalistas que quedan fuera de sus esquemas). La insistencia en esta confrontación (y enfrentamiento) no entre dos partidos, sino entre dos «modelos de sociedad», puede sin embargo llevar a reflexiones preocupantes.

Puede ocurrir que sobre Fraga y AP ejerzan un efecto moderador algunos factores, como por ejemplo la presión de un electorado más inclinado al centro (su existencia está, sin embargo, todavía por demostrar), la probable adquisición de hábitos parlamentarios de una numerosa cohorte de diputados y senadores, el peso de algunos dirigentes nuevos, y sobre todo el papel que tiene su aliado el PDP. El PDP ha conseguido sólo 16 diputados, pero parece querer alcanzar un camino más autónomo, situándose en el centro-derecha.

Sin embargo, precisamente la presencia (y las esperanzas) del PDP, puede hacernos pensar que AP como tal no es capaz de construir una alternativa posible y creíble al PSOE. A no ser que sufra una rápida evolución, AP no puede pretender convertirse en el partido moderado de centro-derecha único capaz de ambicionar sustituir a un partido moderado de izquierdas como el PSOE. El problema de la futura dinámica del sistema político español se encuentra en este nudo.

El sistema de partidos parecía haber cristalizado de una vez por todas después de las elecciones de 1979, que repetían (aparte de la explosión de los nacionalistas) los esquemas de 1977: dos grandes polos en el centro-derecha y en el centro-izquierda, y dos polos menores en los extremos (AP y PCE). Después del 28 de octubre de 1982 este esquema ha saltado por los aires 
y el sistema ha iniciado un proceso de reestructuración. No se puede considerar que esté estructurado de manera estable y duradera, precisamente por la razón que he expuesto: la necesidad de la formación, o transformación, de un partido de derechas que suponga una alternativa democrática creíble.

Si quisiera ceder al gusto de las tipologías, diría que puede hablarse todavia de bipolarización en la sociedad española (una bipolarización fuerte, como le es propio y como es característico de otras sociedades que se la asemejan), pero que no puede hablarse en un sistema de bipartidismo. Para hablar de bipartidismo no sólo faltan las cifras (hay demasiada distancia entre el 25,9 por 100 de AP y el 48,4 por 100 del PSOE), sino que también falta otra condición esencial: la posibilidad de la alternativa. Alternativa que no puede ofrecer, repito, el máximo partido actual de la oposición.

Si se quiere hablar de un tipo de sistema, entonces háblese para la España de 1982, como algunos observadores han propuesto, de un sistema de partido dominante, como es de hecho el PSOE con la avalancha de votos y escaños conseguidos.

La fase de reorganización no se ha cerrado todavía en España. Por el contrario, un sistema partidista tan desequilibrado y falto de una opción conservadora democrática queda abierto a muchas soluciones y suscita problemas que esperemos no se vuelvan dramáticos.

En cuanto a esta última consideración, puede afirmarse, sin embargo, que la victoria del PSOE ha significado la victoria de la democracia, su tan ansiada consolidación. La manera plebiscitaria del voto al PSOE ha sido precisamente ésta: rechazo y condena del golpismo, defensa de la libertad, aspiración a transformar finalmente al Estado franquista. Puedo responder ahora a la pregunta que me había hecho al final del primer parágrafo: la misma afluencia a las urnas ha sido auténtica voluntad de participar en este giro, de dar consenso a la innovación.

No ha habido entusiasmo, como alguno ha subrayado, pero al menos el desencanto se ha desterrado. Ciertamente se ha cerrado la transición, es decir, aquel proceso demasiado lento y penoso de ocaso del régimen autoritario $\mathrm{y}$ de plena afirmación del régimen democrático. 